\title{
Personality and wealth accumulation among older couples: Do dispositional characteristics pay dividends?
}

\author{
Irene Mosca, Cathal McCrory* \\ The Irish Longitudinal Study on Ageing (TILDA), Department of Medical Gerontology, Lincoln Gate, Trinity College Dublin, Dublin 2, Ireland
}

\section{A R T I C L E I N F O}

\section{Article history:}

Received 14 November 2014

Received in revised form 17 February 2016

Accepted 28 April 2016

Available online 3 May 2016

\section{JEL classification:}

G02

D03

D14

D31

PsycINFO Classification:

3120

Keywords:

Personality traits

Big five

Non-cognitive traits

Wealth accumulation

Cohort study

\begin{abstract}
A B S T R A C T
This paper explores whether the 'Big 5' personality characteristics: Emotional Stability, Extraversion, Conscientiousness, Agreeableness, and Openness to Experience, contribute to net household wealth accumulation among 1172 couple pairs $(n=2344)$ participating in The Irish Longitudinal Study on Ageing, independent of other socio-demographic and human capital variables. We employ quantile regression to determine whether the effects of personality vary at different levels of the conditional distribution of wealth. Results reveal that the personality characteristics of the financial respondent to the survey are more strongly associated with wealth than those of the non-financial respondent. Specifically, we find that emotional stability and extraversion are positively associated with wealth at the household level among spousal pairs. We also find that conscientiousness is positively associated with wealth, but the relationship is only significant at the lower end of the wealth continuum. In general, agreeableness and openness are negatively associated with wealth although the relationships are non-significant. These findings indicate that personality is an important factor shaping individuals' consumption preferences and financial decision-making behaviour over the life-course.
\end{abstract}

(c) 2016 Elsevier B.V. All rights reserved.

\section{Introduction}

Recent years have witnessed rapid increases in the proportion of the population living to pension age and beyond. This 'greying' of the population represents a number of challenges for national governments, not the least of which is how to sustain current levels of pension provision at a time when life expectancy is increasing and the number of persons of working age supporting retired persons is falling. A recent report from the International Monetary Fund found that, among advanced economies, expenditure on public pension provision increased from 5\% of GDP in 1970 to $8.5 \%$ of GDP in 2010 (Cottarelli, 2011) and there is growing concern about the future sustainability of public pension provision. It is becoming increasingly clear that governments need to encourage people to plan and provide more for their own retirement. We would argue that it is important to consider the role of dispositional factors (i.e. personality) when attempting to understand the complex nexus of factors that make a person more or less likely to be making financial preparations for their retirement.

\footnotetext{
* Corresponding author.

E-mail address: mccrorc@tcd.ie (C. McCrory).
} 


\subsection{How is personality defined?}

Trait theorists in the factor analytic tradition argue that personality comprises a number of broad dimensions that represent dispositional characteristics that reflect enduring patterns of thoughts, feelings and behaviours (Roberts \& Mroczek, 2008). Although psychometrists continue to debate the higher order structure of personality, there is at least some broad consensus that the main dimensions include extraversion, neuroticism, and conscientiousness; to which five factor advocates would add agreeableness and openness (Caspi, Roberts, \& Shiner, 2005). Extraversion indexes a number of traits that are associated with positive emotionality including warmth, sociability, activity and optimism. Neuroticism reflects a dispositional tendency to experience the world as distressing or threatening and is characterised by anxiety, hostility, and heightened sensitivity to stress. Conscientiousness measures self-discipline, orderliness, competence, and planning. Agreeableness captures a constellation of prosocial tendencies that foster positive relationships with others including trust, altruism, and compliance. Finally, openness reflects a number of traits including intellectual curiosity, imagination, and enjoyment of novelty. A voluminous literature attests to the power of personality for predicting a whole variety of outcomes in later life including educational and occupational success, lifestyle behaviours, subjective health and wellbeing, success in personal relationships, and physical health and longevity (Bogg \& Roberts, 2004; Caspi et al., 2005; Ozer \& Benet-Martinez, 2006). Indeed, a recent meta-analysis concluded that personality traits are as powerful a predictor of mortality, divorce and occupational status as socio-economic status or cognitive ability (Roberts, Kuncel, Shiner, Caspi, \& Goldberg, 2007).

\subsection{The role of non-cognitive traits}

More recently, economists have become interested in the role of non-cognitive traits such as personality characteristics, self-efficacy, and locus of control as predictors of educational attainment, labour market success, lifetime earnings, wealth, and savings behaviour (Brown \& Taylor, 2014; Cobb-Clark, Kassenboehmer, \& Sinning, 2013; Duckworth \& Weir, 2010; Nyhus \& Pons, 2005; Nyhus \& Webley, 2001). This interest stems from an increasing awareness that individual differences in non-cognitive traits may account for some of the unobserved heterogeneity in economic behaviour, preferences, and outcomes (Cobb-Clark \& Schurer, 2012).

For example, Nyhus and Webley (2001) examined the extent to which personality influenced savings and borrowing behaviour among a sample of Dutch households involving 532 couple households and 202 single households. They found that emotional stability (the inverse of neuroticism) was positively associated with liquid savings (i.e. balance on current/ savings accounts), total savings (savings minus debt), and intention to save in the next 12 months. Extraversion was negatively associated with savings and household debt; while agreeableness was negatively associated with savings. Interestingly, conscientiousness was found to be unrelated to either savings or borrowings despite previous studies involving the same longitudinal dataset showing that it was associated with saving behaviour. Nyhus and Webley (2001) speculated that differential attrition in the sample may have constrained their ability to test this hypothesis, as less conscientious individuals might be more likely to be lost at follow-up.

Davey and George (2010), by contrast, found that conscientiousness was the personality trait that was most consistently related to prudent financial planning behaviour in a study from the UK. Another interesting finding to emerge from this study was that agreeableness was associated with having savings. In agreement with Nyhus and Webley (2001), they noted that extraverts were more likely to carry debt, and were less likely to pay off debt before incurring interest charges. Taken in conjunction, these findings suggest that dispositional tendencies associated with this trait (i.e. high sociability, need for stimulation) may lead extraverts to be more profligate in terms of their personal finances.

Nyhus and Pons (2005) examined the extent to which different personality dimensions were rewarded in the labour market using measures of the Big 5 personality factors among respondents to the Dutch Household Survey. They found that emotional stability was associated with higher earnings among men and women, and that agreeableness was associated with lower wages, among women only, after adjustment for human capital variables including education, experience and tenure. Interestingly, they did not observe any positive effects of extraversion or conscientiousness on wages, which were the two personality dimensions they most expected to be rewarded in the labour market. Although they did observe a rather counter-intuitive negative interaction between conscientiousness and tenure on wages, which they speculated might arise because employers interpret educational attainment as a marker of this trait. Hence conscientiousness may be rewarded upon appointment but these individuals will have shallower income curves as experience increases.

Mueller and Plug (2006) estimated the effects of personality on male and female earnings among participants in the Wisconsin Longitudinal Study. They found that personality traits were differentially rewarded in the labour market for men and women. Emotional stability, and antagonism (the inverse of agreeableness) were associated with higher earnings among men ( $4 \%$ and $2 \%$ respectively), but not among women. Conscientiousness by contrast was associated with higher earnings $(+2 \%)$ among women, but not among men. Openness to experience was associated with significantly higher earnings for both men and women, which is perhaps unsurprising as this personality trait is modestly correlated with intelligence (Ackerman \& Heggestad, 1997; Gignac, Stough, \& Loukomitis, 2004).

Duckworth and Weir (2010) examined whether the Big 5 personality dimensions were related to lifetime earnings and household savings behaviour using data from the US Health and Retirement Study (HRS). They found that conscientiousness was associated with a $9 \%$ increase in lifetime earnings net of other factors including education and cognitive variables, while neuroticism was associated with a $5 \%$ penalty in lifetime earnings. Conscientiousness was also an important contributor to 
household wealth net of lifetime earnings and other factors when the investigators undertook an analysis of household wealth using spousal pairs, with the effects of conscientiousness being similar for men and women (+15\%). Agreeableness, by contrast was negatively associated with wealth for both spouses. These investigators noted that personality traits were as powerful as education or cognitive ability in explaining lifetime earnings.

Brown and Taylor (2014) reported significant associations between personality characteristics and the value of unsecured debt and financial assets held in their analyses of couple pairs from the British Household Panel Survey. They found that agreeableness and extraversion were positively associated with the amount of unsecured debt held while conscientiousness was negatively associated with the holding of debt. Extraversion was also found to be negatively associated with the value of assets held, while openness to experience was positively associated with financial asset holding. Finally, Cobb-Clark et al. (2013) found that a high internal locus of control, which measures the extent to which an individual feels they can exert influence over their social environment, was differentially related to wealth accumulation at different levels of the distribution in the Household Income, Labour and Dynamics in Australia Survey. They found that a high level of control was particularly important in the context of wealth accumulation for those at lower levels of the wealth distribution particularly for those at or below the 50th percentile where the net gain was around $\$ 50,000$ (AUS).

\subsection{Is personality exogenous?}

An obvious difficulty with much of this research is that personality is usually measured contemporaneously with the outcome variable(s) so researchers have justifiably questioned whether personality is causal or consequential to economic success. We believe that there are strong reasons for treating personality as an exogenous variable. Firstly, there is abundant evidence reviewed in Bouchard and Loehlin (2001) that personality traits have substantial heritability, with twin correlational studies suggesting heritabilities of $40-60 \%$ for monozygotic twins, and smaller but not insubstantial correlations for dizygotic twins, sibling-sibling pairs, and parent-child pairs. Secondly, individual differences in temperamental traits are evident early in life, and it has been argued convincingly by Rothbart (2007), among others, that the early emerging temperamental dimensions of reactivity, approach/inhibition, and emotional regulation are related to the Big 5 personality factors. Thirdly, there is some support for the idea that personality traits may have a biological locus. For example, there is a strong tradition of psychological research dating back to the seminal work of Hans Eysenck (1967) that extraverts have lower levels of cortical arousal and experience less change in cortical arousal in response to the presentation of stimuli relative to introverts, which, it is alleged, motivates a preference to seek out stimulation to raise levels of cortical arousal (Stelmack \& Rammsayer, 2008). Similarly, there is some tentative evidence emerging from neuroimaging studies that neuroticism may be linked with hyperarousal of the amydala which promotes vigilance for threat and slower extinction of the amydala response to a threatening appraisal (Ormel et al., 2013).

\subsection{How stable is personality over time?}

There is a large psychological literature that supports the idea that personality is relatively stable over time and situations (Conley, 1985; Costa \& McCrae, 1994, 1997; Roberts \& DelVecchio, 2000; Terracciano, McCrae, \& Costa, 2010). There are a number of different methods for assessing the stability of personality dimensions over time including intra-individual stability (i.e. whether an individual remains the same over time), rank-order stability (i.e. whether individuals retain their relative position within a group over time), and mean-level change (i.e. whether groups of people increase or decrease on trait dimensions over time) (Roberts \& DelVecchio, 2000). Conley (1985) examined the longitudinal stability of personality over a long time epoch utilising data for engaged couples who were first assessed in 1935-1938, and were followed up in 19541955, and again in 1980-1981. An interesting feature of this study was that, in addition to self-ratings of personality, couple pairs were asked to rate the personality of their partner, and this was supplemented by an additional phase of data collection whereby respondents were asked to nominate up to 5 friends, who then completed a separate postal questionnaire rating the personality characteristics of the respondent. There was good consistency between self, partner and friend ratings when assessed on the same measurement occasion. For extraversion and neuroticism, the correlations were mostly of the order of $\sim 0.4$ or higher. Conley also noted good agreement between self-ratings on the same trait when assessed almost 20 years apart, with the magnitude of the associations being similar to those recorded for different raters on the same occasion. Finally, respondent scores on the personality dimensions at baseline were found to be moderately correlated with partner ratings almost 20 years later. Cross-respondent, cross-time correlations for extraversion, neuroticism, and impulse control were generally in the region of 0.3 or higher.

Costa and McCrae (1994) combined data from a number of longitudinal studies with time intervals ranging from 6 to 30 years and reported median stability coefficients for the big five dimensions in the order of 0.6 or above. Roberts and DelVecchio (2000) undertook a meta-analysis of 152 longitudinal studies to evaluate the consistency of personality traits over time. They reported population estimates of trait consistency uncorrected for measurement error ranging from 0.35 in early childhood (i.e. less than 3 years of age), increasing through 0.50 in early adulthood, peaking at 0.74 between 50 and 59 years of age, and remaining relatively constant thereafter at 0.71 between 60 and 73 years of age. The rank-order stability of scores on the five main personality dimensions averaged across studies was substantive ranging from 0.50 to 0.54 . In addition, population estimates of trait consistency were found to be fairly similar across different assessment methods - selfreport, observer ratings, and projective tests. Nevertheless, a separate meta-analysis by Ardelt (2000) which examined 206 
personality stability coefficients reported in the literature found rather less support for personality stability noting that stability tends to decrease as the test-retest interval increases, and that personality stability increases between the ages of 30 and 50 years and tends to decline thereafter.

It has been argued that some of the inconsistencies that have emerged across studies arise because the majority of studies that have examined the effects of age on trait stability are cross-sectional in nature. To overcome these limitations, Terracciano et al. (2010) explored the longitudinal stability of personality traits at the intra-individual level using data for some 684 participants aged 17-76 years in the Baltimore Longitudinal Study of Aging (BLSA) who had repeat measures of personality over several decades. They estimated intra-individual change by calculating the individual stability (IS) coefficients between personality traits at time 1 and time $2\left(\mathrm{IS}_{12}\right)$, and at time 2 and time $3\left(\mathrm{IS}_{23}\right)$, and then subtracting the difference between $\mathrm{IS}_{12}$ and $\mathrm{IS}_{23}$. Averaging across the ten personality scales assessed in the BLSA, they found that the mean change in personality across the measurement points was essentially zero. Moreover, changes in IS were close to zero for each of the age groups older than 30 years causing them to conclude that personality stability plateaus in early adulthood and remains relatively constant thereafter.

Although a recent meta-analysis documented mean-level changes in the major personality dimensions over the lifecourse (Roberts, Walton, \& Viechtbauer, 2006), which may or may not be attributable to maturational development (see Costa \& McCrae, 2006), many researchers in the factor analytic tradition would agree that the major traits are relatively stable over time, particularly in older adulthood. It should be acknowledged that stable does not mean immutable as Costa and McCrae (2006) have rightly cautioned as personality has been shown to be responsive to major life events (Mroczek \& Spiro, 2003; Specht, Egloff, \& Schmukle, 2011) leading some to speculate that personality change may represent an individual differences phenomenon with some people remaining more stable than others (Mroczek \& Spiro, 2003). Nevertheless, we hold the same broad view articulated by Cobb-Clark and Schurer (2012) that the Big 5 "may be seen as stable inputs into many economic decisions' (p. 14).

\subsection{Aims and objectives}

The present study will examine whether the Big 5 personality dimensions are independently associated with household wealth accumulation using data for some 1172 couple pairs participating in The Irish Longitudinal Study on Ageing (TILDA), a large prospective population study of ageing in the Republic of Ireland. We focus on wealth because in meritocratic societies, income and wealth are arguably the most common metric applied to judge objective success (Duckworth, Weir, Tsukayama, \& Kwok, 2012). Wealth is a monotonically positive good: ceteris paribus, most individuals would prefer to be wealthier rather than poorer. Wealth accumulation is considered desirable at the individual level because it provides economic security, enables consumption, and protects against income losses (Nabeshima \& Seay, 2015). In most societies, wealth accumulation also carries with it a number of non-economic benefits such as prestige and social influence as it is considered a marker of life success (Cheng \& Tracy, 2013). Nevertheless, many people arrive at the door of retirement with little or no net wealth (Lusardi \& Mitchell, 2007), and demographic factors are not sufficient to explain variations across households as "Households with similar economic and demographic characteristics accumulate radically different amounts of wealth" (Ameriks, Caplin, \& Leahy, 2003; p. 1007). In this context, it is important therefore to investigate whether personality is important in determining how much wealth individuals accumulate over the life-time.

Of particular interest in the context of the present study is whether conscientiousness, a measure of self-discipline and planning behaviour, is associated with wealth accumulation. It is important to acknowledge that the effects of personality can be both direct and indirect. For example, it is well established that conscientious individuals perform better in school (Noftle \& Robins, 2007) which may translate into higher net wealth through its effects on earnings (e.g. Duckworth \& Weir, 2010), in addition to the direct effect of a dispositional preference for future planning (i.e. saving). We also expect that emotional stability will be associated with wealth accumulation as we anticipate that emotionally stable individuals will make more rational choices concerning the importance of planning for their financial future. Given that previous studies have shown that agreeableness is inversely associated with earnings (Nyhus \& Pons, 2005) and savings (Nyhus \& Webley, 2001), we expect that this personality dimension will be negatively associated with wealth. Similarly, we expect that extraversion will be negatively associated with wealth because this personality dimension encompasses a number of facets (e.g. gregariousness, sensation seeking) that may lead extraverts to be more profligate with their finances. Finally, we expect that openness to experience will be positively associated with wealth because this is the personality dimension that is most strongly linked with intelligence, and we might expect that more intelligent individuals will make more informed financial decisions.

We believe this study is important for a number of reasons. Firstly, while studies have documented impacts of personality on earnings, hours worked, and other labour market outcomes, evidence on whether they also predict wealth accumulation is scarce (Cobb-Clark et al., 2013; Duckworth \& Weir, 2010). Secondly, it is entirely possible that the effects of personality may differ across countries as a consequence of different welfare and healthcare systems. For example, many European countries operate universal healthcare systems, so it could be argued that the provision of social programs may disincentivise saving and dilute the effects of personality traits in European populations relative to countries like the US where, until relatively recently, healthcare provision was individual-centred. If it could be shown that the effects of personality are consistent across countries with different confounding structures, then the idea that personality is causal would be enhanced. 
An important difference between our study and that of Duckworth and Weir (2010) is that we examine the impact of personality on couples' wealth accumulation, not for men and women, as they have done, but rather, according to whether they were the designated financial respondent to the survey. ${ }^{1}$ We believe this is an important qualification because it might be expected that the personality traits of the person in the household who is most knowledgeable about household finances will exert a stronger influence on the financial planning behaviour of the couple. Finally, we use quantile regression to examine whether the Big 5 personality dimensions have the same predictive power at different levels of the wealth distribution.

\section{Method}

\subsection{Data}

The data we use are from The Irish Longitudinal Study on Ageing, which is a nationally representative, longitudinal study of community-dwelling individuals aged 50+ living in Ireland. The first wave of data was collected between October 2009 and July 2011. A total of 8504 participants (8175 aged 50+ and 329 younger spouses/partners of eligible individuals) were recruited from a clustered random sample of all households in Ireland (Whelan \& Savva, 2013). Respondents completed a computer-assisted personal interview (CAPI) in their own homes. Respondents were also asked to complete a selfcompletion questionnaire (SCQ), which was designed to explore areas that were considered particularly sensitive, such as relationship quality, loneliness and stressful life events. A total of 6910 respondents aged 50+ completed and returned the SCQ. The overall response rate for the first wave of the study was $62 \%$. The second wave of data was collected between April 2012 and January 2013. A total of 7455 respondents participated and a response rate of $86 \%$ was achieved (Dooley, 2014).

\subsection{Sample}

We exploit two key analytical advantages of TILDA. The first advantage is that if an individual is in the sample, so too is their spouse or partner if they are willing to participate. The second advantage is that in multi-person households, the interviewer first asks who is most knowledgeable in relation to family finances, including matters relating to wealth. This person is designated the 'Financial Respondent' (FR) and is asked to respond to more detailed questions in the financial domain. For this reason, household or couple-specific measures such as housing characteristics or financial wealth are only collected once from each household/couple. In contrast, individual characteristics and attributes such as health status, educational attainment, cognition and personality are collected from each respondent.

Our unit of analysis is married/cohabiting couples. It is important to note that the couples used in our analysis are a relatively homogenous group. Average marriage duration is 35.4 years and only 5 respondents report to have been previously divorced. This is not surprising as divorce became legal in Ireland only in 1997. Our interest is in examining the relationship between personality traits of both the FR and the Non-Financial Respondent (NFR) in relation to matters related to household wealth.

As personality questions were introduced in the SCQ at Wave 2, we use cross-sectional data from the second wave of TILDA and exclude individuals who did not return a SCQ $(N=1181)$ or who returned it without answering a sufficient number of items on each scale to be prorated $(N=209)$. Given that our unit of analysis is married/cohabiting couples, we then exclude individuals who are not part of a couple as they are widowed $(N=764)$, separated/divorced $(N=422)$ or never married $(N=482)$. This leaves a sample of 4397 individuals living in a couple. We have to exclude 1333 of these individuals for a number of reasons. The main reason for exclusion is non-participation of the spouse/partner in TILDA. Another reason is missing values for one or more of the control variables. This leaves a sample of 3064 individuals or 1532 couples.

\subsection{Measurement}

\subsubsection{Wealth}

TILDA collects high-quality wealth information. As wealth data at the individual or household level has not been collected in Ireland since the late 1980s, the TILDA wealth data are rare within Ireland. Within each household, the FR is asked whether or not they (or their spouse/partner) hold, and their valuations of: owner occupied residential property; savings on deposit; financial assets; cars; other residential property; and other types of assets such as farmland and businesses. Flash cards are used so that respondents are sure as to what to include. Questions relating to debt are also asked to the FR and the distinction between mortgage and non-mortgage debt is made so information on both types of debt is collected. More detailed information regarding how wealth is collected can be found in Barrett and O'Sullivan (2014), Hudson, Mosca, and O'Sullivan (2014) and O’Sullivan, Nolan, Barrett, and Dooley (2014).

\footnotetext{
${ }^{1}$ HRS and TILDA ask the person who is most knowledgeable about the finances of the household to complete the household finances module. This module captures information related to household savings, investments, assets (e.g. home ownership), and debts and liabilities.
} 
Unfolding brackets are used in instances where a respondent does not provide a point estimate. Unfolding brackets have been shown to be effective in reducing missing data by allowing the respondent to provide a range (Heeringa, Hill, \& Howell, 1995). We use the mid-points of the unfolding brackets as the inputted data points for those who do not answer the original questions.

The first outcome variable used in our analysis is value of total household net wealth. It is obtained by subtracting nonmortgage debt and mortgage debt from total household gross wealth. The value of total household gross wealth is derived from aggregating the values of: owner occupied residential property; savings on deposit; financial assets (including bonds, shares, mutual funds and life insurance); cars; other residential property; and other types of assets such as farmland and businesses. We then disaggregate net wealth into two components: (i) net housing wealth, which is obtained by subtracting mortgage debt from the value of owner occupied residential property; and (ii) net non-housing wealth, which is the sum of net physical wealth and net financial wealth. ${ }^{2}$ We disaggregate net wealth into these two components because the level of home ownership in Ireland is high relative to other countries. According to Census 2011, around 70\% of all Irish households own their dwelling outright or are paying off a mortgage. As shown by O'Sullivan et al. (2014, p. 341), the level of home ownership is also high among TILDA respondents (85\%). This implies that Irish older individuals are more likely than most of their European counterparts to have accumulated wealth through home ownership.

Our working sample includes 1532 couples. For a total of 360 couples, information on one or more of the wealth components is missing. Our main analysis below is based on the 1172 couples (2344 individuals) where net wealth is not missing. As a robustness check, we then also include couples where net wealth is missing. For these couples, we use a conditional hotdeck procedure to impute the value of the missing wealth component(s). ${ }^{3}$

\subsubsection{Personality traits}

In TILDA, personality traits are measured using the NEO-FFI-3 (Costa \& McCrae, 2004). It is a 60-item self-report instrument that yields scores for each of the Big 5 personality dimensions: Neutoticism, Extraversion, Openness to Experience, Agreeableness and Conscientiousness. Each scale comprises 12 items and respondents are required to indicate the extent to which they agree with each statement on a 5 point likert-scale ranging from strongly agree through neutral to strongly disagree. Responses to each item are scored 0-4 so that the total score for each scale ranges from 0 to 48 with higher scores indicating higher levels of the trait. Scale scores are pro-rated if the respondent is missing three or fewer items on each dimension of the questionnaire. The test authors report internal consistency reliability coefficients for the various scales ranging from 0.75 to 0.82 with 57 of the 60 items loading greater than 0.40 on their designated factor and the remaining 3 items loading just less than 0.40 (Costa \& McCrae, 2004). The five factor structure of the NEOFFI has been affirmed in a number of studies and across different cultures (McCrae, 2002).

In order to mitigate against the potential problem of life-cycle effects influencing personality traits and the subsequent measurement error this might induce, we follow the literature in the economics domain (Brown \& Taylor, 2014; Nyhus \& Pons, 2005; Osborne Groves, 2005) and condition each personality trait on a polynomial in age. We then standardise the resulting residuals so that they have a mean of zero and a standard deviation of one and use them as indicators of personality net of life-cycle influences. In the following, we refer to these age-effect-free personality variables as r-emotional stability, $r$ extraversion, r-openness, r-agreeableness and r-conscientiousness.

\subsubsection{Other regressors}

While our focus is on personality traits, we also control for other characteristics that have been found to be important determinants of wealth accumulation. Focusing first on individual characteristics, we include separate individual-level control variables for both the FR and the NFR. Educational attainment of each spouse/partner is accounted for by the age at which the respondent left full-time education. We also capture whether the respondent is currently in employment (either as an employee or self-employed); retired or 'other'. The 'other' category includes individuals who are permanently sick and disabled, unemployed, home makers and in education or training. In our regression analyses, the reference category includes individuals who are in employment. Following Smith, McArdle, and Willis (2010) and Duckworth and Weir (2010), we include a measure of working memory as the ability to recall information requires working memory capacity and serves as a proxy measure for cognitive status. As measure of memory, we employ delayed word recall: respondents are read a list of ten simple nouns and are subsequently asked to recall as many of the original words as possible. We also control for selfrated childhood socio-economic position (SEP) to take account of the fact that contemporaneous wealth may also reflect aspects of inheritance. To the best of our knowledge, only the study by Brown and Taylor (2014) controlled for childhood SEP. TILDA respondents are asked to indicate whether they grew up in a family which was: 'pretty well-off', 'about average' or 'poor'. The reference category is grew up 'pretty well-off.

We then include household-level variables for: geographic location; number of children and income. Geographic location is included to control for regional differences in asset prices, primarily housing. Three dummy variables are used according to whether the couple lives in Dublin, in an urban area outside Dublin or in a rural area. The reference category is Dublin. To account for the relationship between family structure and household wealth, we control for the number of children. Finally,

\footnotetext{
${ }^{2}$ The sum of net housing wealth and net non-housing wealth is equal to net wealth.

${ }^{3}$ We use the hotdeckvar algorithm in STATA 12 (Schonlau, 2005) and replace missing values with values randomly selected from donor observations.
} 
Table 1

Distribution of net wealth, net housing wealth and net non-housing wealth.

\begin{tabular}{llll}
\hline & Net wealth & Net housing wealth & Net non-housing wealth \\
\hline Q10 & 92,000 & 50,000 & 500 \\
Q25 & 172,250 & 140,000 & 15,000 \\
Q50 (median) & 310,350 & 200,000 & 65,000 \\
Q75 & 528,750 & 300,000 & 225,000 \\
Q90 & 920,000 & 450,000 & 515,000 \\
Mean & 450,709 & 241,977 & 208,873 \\
\% with below average value & $70.0 \%$ & $60.0 \%$ & $72.3 \%$ \\
\% with non-positive value & $2.0 \%$ & $5.4 \%$ & $9.5 \%$ \\
\hline
\end{tabular}

we include a measure of weekly gross individual income, which is collected through a series of questions covering labour income and income from social welfare, pensions, investment incomes and other sources (O'Sullivan et al., 2014). ${ }^{4}$ The questions are taken directly from the recent versions of the European Union Statistics on Income and Living Conditions (EU-SILC) questionnaire. Income questions are asked to both the FR and NFR. We first compute weekly individual income for each spouse/partner within each household and then sum them to estimate the couple's aggregated income. O'Sullivan et al. (2014) have shown that the medians and means of equivalised weekly household income from the TILDA and EU-SILC samples appear similar when using the aggregated sources of gross income approach. As we use a similar approach in calculating couples' aggregated income in our paper, we are confident the income data collected in TILDA and used in our analysis is reliable.

\subsection{Wealth distribution and statistical analysis}

Table 1 illustrates summary statistics for net wealth, net housing wealth and net non-housing wealth.

One can see that, unsurprisingly, the distribution of wealth is skewed at the top end, with between two thirds and three quarters of couples having a value of net wealth, net housing wealth or net non-housing wealth below the average value. One solution to the problem of right skewness in wealth is to take a logarithmic transformation. However, this transformation is troublesome for couples with negative or zero wealth. As Table 1 shows, for example, $9.5 \%$ of couples have non-positive net non-housing wealth. An alternative solution is to transform wealth with the inverse hyperbolic sine function, as initially suggested by Burbridge, Magee, and Robb (1988) and subsequently employed by Carroll, Dynan, and Krane (2003) and Pence (2006). The inverse hyperbolic sine of wealth $w$ is:

$$
g[w, \varepsilon]=\frac{\ln \left[\varepsilon w+\left(\varepsilon w^{2}+1\right)^{1 / 2}\right]}{\varepsilon}
$$

where $\varepsilon$ is an estimated scale parameter. ${ }^{5}$ Like the logarithmic transformation, $g[w, \varepsilon]$ downweights large values of wealth but has the advantage of retaining zero and negative values found in the original data. As is shown in Fig. 1, the distribution of net wealth after using this transformation is reasonably symmetric.

We then model (transformed) wealth using quantile regression methods. As highlighted by Cameron and Trivedi (2010) and Davino, Furno, and Vistocco (2014), this approach allows one to study the impact of the regressors at different levels of the conditional distribution of the outcome variable, thereby allowing a richer understanding of the data. Using this method, we can investigate whether the effect of personality traits on wealth accumulation differs at different quantiles of the conditional distribution. In particular, we can investigate whether certain personality traits are more important for couples at the bottom of the wealth distribution as opposed to couples at the top of the distribution. For a given conditional quantile $\theta$ of (transformed) net wealth, the quantile regression can be formulated as follows:

$$
Q_{\theta}(W \mid \mathbf{X})=\mathbf{X} \boldsymbol{\beta}(\theta)
$$

where $0<\theta<1$ and $Q_{\theta}$ (.I.) denotes the conditional quantile function for the $\theta$-th quantile of (transformed) net wealth $W$. We estimate quantile models at the 10th, 25th, 50th, 75th and 90th quantiles of the conditional distribution of (transformed) net wealth.

\footnotetext{
${ }^{4}$ Labour income consists of employee income from the respondent's main job in the past twelve months and the gross profit from self-employment for selfemployed people as well as pre-tax farm income for those engaged in farming. Pension income is made up of both regular and lump sum income from occupational and private schemes. Social welfare payments made to the respondent, income from assets and irregular income are also included in our measure of gross income.

${ }^{5}$ We set $\varepsilon$ to 0.00001 in our analysis.
} 


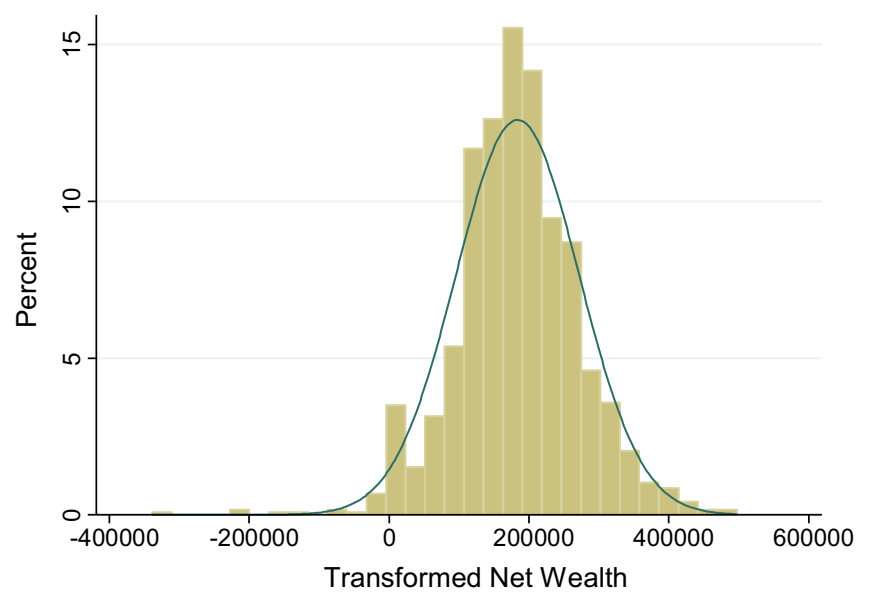

Fig. 1. Distribution of net wealth transformed using the inverse hyperbolic sine function.

\section{Results}

\subsection{Descriptive statistics}

Summary statistics of the individual and household characteristics of the 2344 individuals or 1172 couples in our sample are reported in Table 2. For individual characteristics, we report the mean or proportion, and standard deviation, for both the FR and the NFR. We use the standard notation to indicate whether the differences in the characteristics of the FR and NFR are statistically significant at: ${ }^{* *} 1 \%$ level; ${ }^{* *} 5 \%$ level; ${ }^{*} 10 \%$ level. For household-level characteristics, we simply report the mean or proportion, and standard deviation in square brackets.

Table 2 shows that FR's score higher than NFR's on emotional stability and openness. Also, in comparison to NFR's, FR's are: more likely to be males; older; more educated; more likely to be retired, but less likely to be in the 'other' category, and score higher in the memory task. There are no statistically significant differences for SEP in childhood among financial and

Table 2

Summary statistics of personality traits and other characteristics.

\begin{tabular}{|c|c|c|}
\hline & Financial Respondent (FR) & Non-Financial Respondent (NFR) \\
\hline \multicolumn{3}{|l|}{ Individual-level characteristics } \\
\hline \multicolumn{3}{|l|}{ Personality traits } \\
\hline Emotional stability score, mean & $42.6[7.2]^{* * *}$ & $41.5[7.4]$ \\
\hline Extraversion score, mean & $28.4[5.6]$ & $28.6[5.7]$ \\
\hline Openness score, mean & $28.1[5.7]^{*}$ & $27.7[6.0]$ \\
\hline Agreeableness score, mean & $33.4[5.1]$ & $33.6[5.2]$ \\
\hline Conscientiousness score, mean & $33.7[5.2]$ & $33.4[5.5]$ \\
\hline Male & $0.58[0.49]^{* * *}$ & $0.42[0.49]$ \\
\hline Age, mean & $63.2[8.6]^{* *}$ & $62.7[8.9]$ \\
\hline Age left education, mean & $17.3[3.0]^{* * *}$ & $16.8[2.6]$ \\
\hline Delayed word recall, mean & $6.4[2.3]^{* *}$ & $6.2[2.5]$ \\
\hline \multicolumn{3}{|l|}{ Labour market status } \\
\hline Employed & $0.37[0.48]$ & $0.38[0.49]$ \\
\hline Retired & $0.42[0.49]^{* * *}$ & $0.35[0.48]$ \\
\hline Other & $0.21[0.41]^{* * *}$ & $0.27[0.44]$ \\
\hline \multicolumn{3}{|l|}{ Socio-economic position in childhood } \\
\hline Grew up in well-off family & $0.10[0.30]$ & $0.09[0.29]$ \\
\hline Grew up in average family & $0.70[0.46]$ & $0.70[0.46]$ \\
\hline Grew up in poor family & $0.20[0.40]$ & $0.20[0.40]$ \\
\hline \multicolumn{3}{|l|}{ Household-level characteristics } \\
\hline \multicolumn{3}{|l|}{ Location } \\
\hline Dublin & $0.26[0.44]$ & \\
\hline Urban outside Dublin & $0.25[0.43]$ & \\
\hline Rural & $0.49[0.50]$ & \\
\hline Number of children, mean & $3.3[1.8]$ & \\
\hline Weekly gross income (FR + NFR), mean & $1116.5[1222.3]$ & \\
\hline$N$ & 1172 & 1172 \\
\hline
\end{tabular}

Notes: proportions are reported unless otherwise indicated. Standard deviations are reported in squared brackets. Differences between financial and nonfinancial respondents significant at: ${ }^{* * *} 1 \%$ level; ${ }^{* *} 5 \%$ level; * $10 \%$ level. 
non-financial respondents. Around $10 \%$ of respondents report they grew up in a pretty well-off family. This compares to around $70 \%$ and $20 \%$ reporting that they grew up in an average, or poor family, respectively.

\subsection{Quantile regression results}

In this Section, we report our empirical results which describe the relation of personality traits of both spouses/partners to wealth accumulation. We first focus on net wealth and then turn to net housing wealth and net non-housing wealth.

\subsubsection{Net wealth}

Table 3 reports the results of the quantile regression for (transformed) net wealth. Focusing on personality traits, results are presented for the residual of the personality measures obtained from conditioning the personality traits on a polynomial function in age.

It is evident from the results of Table 3 that the personality traits of the FR appear to be strongly related to the accumulation of net wealth. In contrast, no meaningful associations are found for the NFR. Also, while emotional stability and extraversion of the FR have positive impacts at higher conditional quantiles of net wealth, conscientiousness is particularly important for households at the bottom of the distribution of net wealth. Between 0.168 and 0.187 of (transformed) net wealth variance is explained by our model. If personality traits are not controlled for, the wealth variance explained reduces by 0.01-0.02 points. Similar changes in the proportion of variance explained are found when educational attainment is not controlled for. This reinforces the importance of the FR personality traits in determining wealth accumulation. ${ }^{6}$

Education has a consistent positive effect across the whole wealth distribution, with the exception of the 10th quantile. Similarly, households where either the FR or the NFR are in the 'other' category of labour market status, which includes individuals who are permanently sick or disabled, unemployed, homemakers or in education and training, are worse-off compared to households where either the FR or the NFR is in employment. Also, geographic location is an important determinant of wealth accumulation, with a household located in Dublin showing higher levels of wealth. This result is in line with our expectations as in Ireland, house prices are significantly higher in Dublin than in other areas. SEP in childhood is also an important determinant of wealth accumulation. Low SEP in childhood is associated with lower levels of wealth in later life. The magnitude of the associations of personality traits with accumulated net wealth is relatively small compared to that of other characteristics such as labour market status or SEP in childhood. For example, at the 50th quantile, high SEP in childhood among financial respondents is associated with an accumulation of net wealth which is around 26,000 euro larger than the accumulation of financial respondents with a low SEP in childhood. This correlation is around four to five times larger than that found for extraversion and emotional stability.

Next, we investigate whether results are robust when we re-estimate the model including: (i) the Big5 of the FR only; (ii) the Big5 of the NFR only; and (iii) the mean of each element of the Big5 between the couple. Results are presented in Table 4. In general, our findings are confirmed. As can be seen in Table 4, Panel 1, emotional stability, extraversion and conscientiousness of the FR are associated with greater net wealth at various quintiles of the conditional wealth distribution. Considerably weaker associations are found for the NFR, with the exception of emotional stability, as illustrated in Table 4, Panel 2. Once again, emotional stability, extraversion and conscientiousness are positively and significantly associated with the accumulation of net wealth when the personality traits of the FR and NFR are averaged, as can be seen in Table 4, Panel 3. It is obvious however that the personality traits of the FR are driving the associations when personality scores are averaged across couples. $^{7}$

As an additional robustness check, we also re-estimate the model of Table 3 based on a sample that includes observations where one or more components of wealth have been imputed $(N=1532)$. As Table A1 illustrates, the personality traits of the FR are still strongly associated with the couple's wealth accumulation and emotional stability, extraversion and consciousness are the three key traits.

\subsubsection{Net housing wealth and net non-housing wealth}

We also perform additional supplementary analyses to determine whether the results are similar when we decompose net wealth into (transformed) net housing wealth (Table 5) and net non-housing wealth (Table 6). As for net wealth, we also investigate whether results are robust when the models are re-estimated including: (i) the Big5 of the FR only; (ii) the Big5 of the NFR only; and (iii) the mean of each element of the Big5 between the couple. Results are presented in Tables A2 and A3 for net housing wealth and net non-housing wealth, respectively.

A number of key results emerge. First, emotional stability and conscientiousness of the FR are once again strong determinants of wealth accumulation. While emotional stability is significantly correlated with net housing wealth (Table 5), conscientiousness is significantly correlated with net non-housing wealth (Table 6). Second, openness of the FR is associated

\footnotetext{
${ }^{6}$ In alternative analyses, we employed ordinary least square regressions to estimate the association of personality traits and transformed net wealth. Results were very similar to the results of quantile regression at the median. This finding was in line with our expectations are the median and the mean of transformed net wealth are closely aligned. Results are not reported in the paper but are available on request.

7 In alternative specifications, we also interacted the FR Big5 with gender to investigate whether it matters whether the FR is male or female. The results showed that these interactions were not statistically significant. The only exception was for conscientiousness, as it appeared that conscientiousness had a positive influence on net wealth accumulation at lower quantiles when the FR is female. Results are not reported in the paper but are available on request.
} 
Table 3

Quantile regression results for (transformed) net wealth.

\begin{tabular}{|c|c|c|c|c|c|c|c|c|c|c|}
\hline & \multicolumn{2}{|l|}{ Q10 } & \multicolumn{2}{|l|}{ Q25 } & \multicolumn{2}{|l|}{ Q50 } & \multicolumn{2}{|l|}{ Q75 } & \multicolumn{2}{|l|}{ Q90 } \\
\hline & $\beta$ & $t$ stat & $\beta$ & $t$ stat & $\beta$ & $t$ stat & $\beta$ & $t$ stat & $\beta$ & $t$ stat \\
\hline \multicolumn{11}{|l|}{ Individual-level characteristics } \\
\hline \multicolumn{11}{|l|}{ Personality traits } \\
\hline r-Emotional stability, FR & 6979 & $(1.60)$ & 5924 & $(1.64)$ & $5606^{* *}$ & $(2.23)$ & $5599^{*}$ & $(1.83)$ & $12,479^{* *}$ & $(2.38)$ \\
\hline r-Extraversion, FR & 642 & $(0.16)$ & 3233 & $(1.00)$ & $6359^{* *}$ & $(2.31)$ & $6281^{* *}$ & $(2.03)$ & 6494 & $(1.52)$ \\
\hline r-Openness, FR & -4169 & $(-1.11)$ & 909 & $(0.32)$ & -3589 & $(-1.27)$ & -929 & $(-0.27)$ & -3519 & $(-1.04)$ \\
\hline r-Agreeableness, FR & -1625 & $(-0.32)$ & -1159 & $(-0.47)$ & -449 & $(-0.17)$ & -691 & $(-0.21)$ & -2775 & $(-0.69)$ \\
\hline r-Conscientiousness, FR & $10,532^{* * *}$ & $(2.62)$ & 4204 & $(1.45)$ & 1513 & $(0.58)$ & -734 & $(-0.24)$ & 94 & $(0.02)$ \\
\hline r-Emotional stability, NFR & -1902 & $(-0.32)$ & -298 & $(-0.08)$ & 4231 & $(1.52)$ & 3912 & $(1.17)$ & 6370 & $(1.53)$ \\
\hline r-Extraversion, NFR & -3782 & $(-0.80)$ & 49 & $(0.02)$ & -1262 & $(-0.42)$ & 1368 & $(0.34)$ & -3743 & $(-0.75)$ \\
\hline r-Openness, NFR & -2543 & $(-0.42)$ & -1230 & $(-0.39)$ & 3545 & $(1.24)$ & -2175 & $(-0.77)$ & 1958 & $(0.37)$ \\
\hline r-Agreeableness, NFR & 1070 & $(0.23)$ & -3850 & $(-1.27)$ & -3678 & $(-1.31)$ & -2489 & $(-0.73)$ & -4770 & $(-1.01)$ \\
\hline r-Conscientiousness, NFR & 4274 & $(0.76)$ & 4283 & $(1.29)$ & 2475 & $(0.73)$ & -486 & $(-0.15)$ & 2364 & $(0.58)$ \\
\hline Age, FR & $2312^{* * *}$ & $(2.62)$ & $1733^{* * *}$ & $(2.58)$ & 695 & $(1.37)$ & $1346^{*}$ & $(1.86)$ & 1335 & $(1.53)$ \\
\hline Age, NFR & 773 & $(1.04)$ & 411 & $(0.60)$ & 715 & $(1.35)$ & 388 & $(0.49)$ & -541 & $(-0.59)$ \\
\hline Age left education, FR & 2604 & $(1.44)$ & $3115^{* *}$ & $(2.14)$ & $4523^{* * *}$ & $(4.38)$ & $6448^{* * *}$ & $(5.83)$ & $7063^{* * *}$ & $(4.64)$ \\
\hline Age left education, NFR & 2507 & $(1.03)$ & $3882^{* *}$ & $(2.47)$ & $3897^{* * *}$ & (3.25) & $4141^{* * *}$ & $(2.92)$ & $4161^{* *}$ & $(2.50)$ \\
\hline Delayed word recall, FR & $4017^{* *}$ & $(2.45)$ & 1511 & $(1.29)$ & -131 & $(-0.10)$ & -1294 & $(-0.88)$ & -3606 & $(-1.58)$ \\
\hline \multirow{2}{*}{\multicolumn{11}{|c|}{ Labour market status }} \\
\hline & & & & & & & & & & \\
\hline Employed, FR & Ref. & & Ref. & & Ref. & & Ref. & & Ref. & \\
\hline Retired, FR & 5605 & $(0.46)$ & 4432 & $(0.64)$ & 3151 & $(0.40)$ & -9677 & $(-1.16)$ & -8734 & $(-0.84)$ \\
\hline Other, FR & $-52,810^{* * *}$ & $(-3.65)$ & $-32,263^{* * *}$ & $(-3.24)$ & $-26,512^{* * *}$ & $(-3.35)$ & $-34,764^{* * *}$ & $(-3.92)$ & $-39,725^{* * *}$ & $(-2.92)$ \\
\hline Employed, FR & Ref. & & Ref. & & Ref. & & Ref. & & Ref. & \\
\hline Retired, NFR & $-32,257^{* * *}$ & $(-3.09)$ & $-20,662^{* * *}$ & $(-3.03)$ & $-18,811^{* * *}$ & $(-2.66)$ & $-14,340^{*}$ & $(-1.72)$ & $-27,375^{* *}$ & $(-2.47)$ \\
\hline Other, NFR & $-37,607^{* * *}$ & $(-2.92)$ & $-25,979^{* * *}$ & $(-3.30)$ & $-21,751^{* * *}$ & $(-3.43)$ & $-24,595^{* * *}$ & $(-3.17)$ & $-47,451^{* * *}$ & $(-4.43)$ \\
\hline \multicolumn{11}{|c|}{ 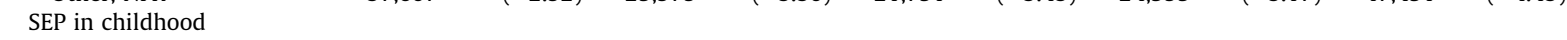 } \\
\hline Well-off family, FR & Ref. & & Ref. & & Ref. & & Ref. & & Ref. & \\
\hline Average family, FR & 13,055 & $(0.82)$ & -5393 & $(-0.54)$ & -5781 & $(-0.53)$ & $-24,356^{*}$ & $(-1.96)$ & $-44,722^{* *}$ & $(-2.22)$ \\
\hline Poor family, FR & 185 & $(0.01)$ & $-26,030^{* *}$ & $(-2.32)$ & $-26,056^{* *}$ & $(-2.19)$ & $-30,999^{* *}$ & $(-2.18)$ & $-57,468^{* *}$ & $(-2.49)$ \\
\hline Well-off family, NFR & Ref. & & Ref. & & Ref. & & Ref. & & Ref. & \\
\hline Average family, NFR & $-24,840$ & $(-1.54)$ & $-19,264^{*}$ & $(-1.69)$ & $-20,822^{* *}$ & $(-2.20)$ & $-14,017$ & $(-1.58)$ & -7253 & $(-0.55)$ \\
\hline Poor family, NFR & $-28,999$ & $(-1.61)$ & $-27,852^{* *}$ & $(-2.29)$ & $-33,536^{* * *}$ & $(-3.11)$ & $-31,814^{* * *}$ & $(-3.05)$ & $-26,333^{*}$ & $(-1.76)$ \\
\hline \multicolumn{11}{|l|}{ Household-level characteristics } \\
\hline Number of children & 412 & $(0.19)$ & -891 & $(-0.61)$ & -867 & $(-0.51)$ & 1177 & $(0.65)$ & 1930 & $(0.75)$ \\
\hline \multicolumn{11}{|l|}{ Location } \\
\hline Dublin & Ref. & & Ref. & & Ref. & & Ref. & & Ref. & \\
\hline Urban outside Dublin & $-15,895$ & $(-1.18)$ & $-34,574^{* * *}$ & $(-4.44)$ & $-36,298^{* * *}$ & $(-5.70)$ & $-37,481^{* * *}$ & $(-5.15)$ & $-38,735^{* * *}$ & $(-4.12)$ \\
\hline Rural & -9757 & $(-0.86)$ & $-28,444^{* * *}$ & $(-3.99)$ & $-29,569^{* * *}$ & $(-4.74)$ & $-20,683^{* * *}$ & $(-3.43)$ & -9893 & $(-0.78)$ \\
\hline Log weekly income & $16,230^{* *}$ & $(2.25)$ & 7474 & $(1.35)$ & -1160 & $(-0.45)$ & -3675 & $(-1.06)$ & -7020 & $(-1.19)$ \\
\hline Constant & $-269,499^{* * *}$ & $(-2.68)$ & $-108,051^{* *}$ & $(-1.98)$ & 25,719 & $(0.51)$ & 33,570 & $(0.62)$ & $191,561^{* *}$ & $(2.32)$ \\
\hline Pseudo $R^{2}$ & 0.187 & & 0.168 & & 0.163 & & 0.177 & & 0.179 & \\
\hline Personality $\Delta$ Pseudo $R^{2}$ & 0.019 & & 0.015 & & 0.014 & & 0.012 & & 0.011 & \\
\hline$N$ & 1172 & & 1172 & & 1172 & & 1172 & & 1172 & \\
\hline
\end{tabular}

Abbreviations: FR: financial respondent; NFR: non-financial respondent; Ref: reference category; SEP: socio-economic position.

Notes: $t$ statistics in parentheses; ${ }^{*} p<0.10,{ }^{* *} p<0.05,{ }^{* * * *} p<0.01$; bootstrapped standard errors computed. Net wealth has been transformed with the inverse hyperbolic sine function. Each of the personality traits has been conditioned on a polynomial in age to net out life cycle influences. The resulting personality trait is based on the standardised residual from this process, i.e. zero mean and unit standard deviation. Personality $\Delta$ Pseudo $R^{2}$ is the difference between the Pseudo $R^{2}$ of the model including all covariates and the Pseudo $R^{2}$ of the model including all covariates except personality traits.

with net non-housing wealth (Table 6). This association is negative and larger in magnitude at higher quantiles. Third, the personality traits of the FR are more important than those of the NFR in shaping the accumulation of net housing wealth and net non-housing wealth (Tables A2 and A3). In caveating these results, it is important to point out that there is not a large degree of portfolio diversification in Ireland with regards to the holding of financial assets. Indeed, previous studies involving the TILDA cohort have shown that owner-occupied housing wealth accounts for about $70 \%$ of TILDA respondents' total wealth (Hudson et al., 2014). Disaggregating net wealth in this manner may not be the most optimal manner to analyse the results. Consequently, in the section that follows, we limit our commentary to discussion of results for net wealth, unless otherwise specified.

\section{Discussion}

This study found reasonably large effects of certain personality traits on wealth accumulation at the household level net of other human capital variables. As discussed in the introduction, some of the effects of personality may be indirect. For 
Table 4

Quantile regression results for (transformed) net wealth controlling for: personality traits of FR only (Panel1); personality traits of NFR only (Panel 2); averaged personality traits of FR and NFR (Panel 3).

\begin{tabular}{|c|c|c|c|c|c|c|c|c|c|c|}
\hline & \multicolumn{2}{|l|}{ Q10 } & \multicolumn{2}{|l|}{ Q25 } & \multicolumn{2}{|l|}{ Q50 } & \multicolumn{2}{|l|}{ Q75 } & \multicolumn{2}{|l|}{ Q90 } \\
\hline & $\beta$ & $t$ stat & $\beta$ & t stat & $\beta$ & $t$ stat & $\beta$ & t stat & $\beta$ & t stat \\
\hline \multicolumn{11}{|c|}{ Panel 1: personality traits of FR only } \\
\hline r-Emotional stability, FR & $8206^{*}$ & $(1.74)$ & $6053^{*}$ & $(1.70)$ & $3967^{*}$ & $(1.71)$ & 5258 & $(1.32)$ & $11,153^{* *}$ & $(2.28)$ \\
\hline r-Extraversion, FR & 2827 & $(0.61)$ & 2238 & $(0.72)$ & $6882^{* * *}$ & $(2.69)$ & 5898 & $(1.62)$ & 6905 & $(1.54)$ \\
\hline r-Openness, FR & -981 & $(-0.24)$ & 627 & $(0.20)$ & 285 & $(0.10)$ & -1844 & $(-0.61)$ & -3808 & $(-1.20)$ \\
\hline r-Agreeableness, FR & -1704 & $(-0.32)$ & 342 & $(0.10)$ & 752 & $(0.27)$ & -1164 & $(-0.34)$ & -2263 & $(-0.67)$ \\
\hline r-Conscientiousness, FR & 7728 & $(1.53)$ & $6920^{* *}$ & $(2.30)$ & 2323 & $(1.05)$ & 2106 & $(0.51)$ & -1995 & $(-0.46)$ \\
\hline Pseudo $R^{2}$ & 0.167 & & 0.152 & & 0.153 & & 0.166 & & 0.173 & \\
\hline Personality $\Delta$ Pseudo $R^{2}$ & 0.016 & & 0.011 & & 0.012 & & 0.008 & & 0.018 & \\
\hline \multicolumn{11}{|c|}{ Panel 2: personality traits of NFR only } \\
\hline r-Emotional stability, NFR & 240 & $(0.05)$ & 4020 & $(1.30)$ & $6060^{* *}$ & $(1.98)$ & $5286^{*}$ & $(1.90)$ & 1574 & $(0.35)$ \\
\hline r-Extraversion, NFR & -215 & $(-0.04)$ & 1673 & $(0.51)$ & -2896 & $(-0.92)$ & 2870 & $(0.85)$ & 2126 & $(0.40)$ \\
\hline r-Openness, NFR & -2280 & $(-0.53)$ & -1851 & $(-0.53)$ & 4117 & $(1.63)$ & -1651 & $(-0.61)$ & -2361 & $(-0.50)$ \\
\hline r-Agreeableness, NFR & -1182 & $(-0.23)$ & -3390 & $(-1.20)$ & -3658 & $(-1.47)$ & -1897 & $(-0.68)$ & 3992 & $(1.00)$ \\
\hline r-Conscientiousness, NFR & 6956 & $(1.27)$ & 2699 & $(0.73)$ & 4018 & $(1.22)$ & 274 & $(0.10)$ & 1914 & $(0.49)$ \\
\hline Pseudo $R^{2}$ & 0.155 & & 0.144 & & 0.146 & & 0.164 & & 0.158 & \\
\hline Personality $\Delta$ Pseudo $R^{2}$ & 0.004 & & 0.003 & & 0.005 & & 0.006 & & 0.003 & \\
\hline \multicolumn{11}{|c|}{ Panel 3: personality traits of FR and NFR (averaged) } \\
\hline Emotional stability, FR\&NFR & 6393 & $(1.02)$ & 5684 & $(1.64)$ & $6294^{* *}$ & $(2.47)$ & $6215^{*}$ & $(1.81)$ & 7802 & $(1.60)$ \\
\hline Extraversion, FR\&NFR & -271 & $(-0.06)$ & 2243 & $(0.66)$ & $4930^{*}$ & $(1.67)$ & $5568 *$ & $(1.72)$ & 4242 & $(0.90)$ \\
\hline Openness, FR\&NFR & -5004 & $(-1.23)$ & -263 & $(-0.09)$ & 1889 & $(0.73)$ & -3371 & $(-1.10)$ & -4663 & $(-1.06)$ \\
\hline Agreeableness, FR\&NFR & -3769 & $(-0.89)$ & -3578 & $(-1.30)$ & -524 & $(-0.18)$ & -2862 & $(-1.05)$ & -2835 & $(-0.64)$ \\
\hline Conscientiousness, FR\&NFR & $11,275^{* *}$ & $(2.22)$ & $7701^{* *}$ & $(2.49)$ & 1383 & $(0.44)$ & 1128 & $(0.35)$ & 2211 & $(0.47)$ \\
\hline Pseudo $R^{2}$ & 0.167 & & 0.151 & & 0.152 & & 0.170 & & 0.167 & \\
\hline Personality $\Delta$ Pseudo $R^{2}$ & 0.016 & & 0.010 & & 0.011 & & 0.011 & & 0.012 & \\
\hline$N$ & 1172 & & 1172 & & 1172 & & 1172 & & 1172 & \\
\hline
\end{tabular}

Abbreviations: FR: financial respondent; NFR: non-financial respondent.

Notes: $t$ statistics in parentheses; ${ }^{*} p<0.10,{ }^{* *} p<0.05,{ }^{* * *} p<0.01$; bootstrapped standard errors computed. Net wealth has been transformed with the inverse hyperbolic sine function. Each of the personality traits has been conditioned on a polynomial in age to net out life cycle influences. The resulting personality trait is based on the standardised residual from this process, i.e. zero mean and unit standard deviation. The controls listed in Section 2.3.3 were also included. Personality $\Delta$ Pseudo $R^{2}$ is the difference between the Pseudo $R^{2}$ of the model including all covariates and the Pseudo $R^{2}$ of the model including all covariates except personality traits.

example, conscientious individuals are more likely to succeed in school, and academic achievement generally attracts a wage premium so controlling for education may lead to a underestimation of the total effect of conscientiousness. Moreover, the effects of personality characteristics differed at different levels of the conditional wealth distribution. Emotional stability, extraversion, and conscientiousness were found to be positively associated with household wealth.

\subsection{Financial Respondent (FR) vs Non-Financial Respondent (NFR)}

A consistent message to emerge was that the personality traits of the FR were more important predictors of wealth accumulation than those of the NFR. Table 3 revealed that the personality characteristics of the NFR do not significantly predict wealth when adjusted for the personality characteristics of the FR. This finding is in line with our hypothesis that the personality traits of the individual designated the person most knowledgeable about the household finances will exert more of an influence on a variable that constitutes a long run indicator of financial planning behaviour (i.e. wealth accumulation). It is noteworthy that, in addition to having a higher mean number of years of education, the FR scored significantly higher on the emotional stability scale of the NEO-FFI-3 compared with the NFR (Table 2). These findings are potentially informative because they suggest that a rational choice is occurring within couple pairs that the more educated and emotionally stable of the dyad assumes the responsibility for managing the household finances. This argument is further bolstered by the finding that the FR scored significantly higher on the openness to experience dimension. Indeed, some researchers have argued that this personality factor is not truly independent because it correlates moderately (in the $0.30-0.40$ range) with measures of cognitive/psychometric ability (Ackerman \& Heggestad, 1997; Gignac et al., 2004).

Of course, it could be argued that the pattern of results we have observed reflect nothing more than the fact that individuals with certain personality characteristics tend to select/attract partners with similar traits (i.e. assortative mating). There are at least 2 lines of evidence that militate against this explanation. Firstly, the personality traits of the NFR were not significantly or consistently associated with wealth accumulation even when the personality traits of the FR were excluded from the models (Table 4). Secondly, in this study we were able to directly examine the extent to which personality scores were correlated within couple pairs. Consistent with the previous psychological literature (Luo \& Klohnen, 2005; Watson et al., 2004) we found that the correspondence between scores on the personality domains for couple pairs were universally low, ranging from 0.08 to 0.23 (emotional stability $r=0.15$; extraversion $r=0.14$; openness to experience $r=0.23$; 
Table 5

Quantile regression results for (transformed) net housing wealth.

\begin{tabular}{|c|c|c|c|c|c|c|c|c|c|c|}
\hline & \multicolumn{2}{|l|}{ Q10 } & \multicolumn{2}{|l|}{ Q25 } & \multicolumn{2}{|l|}{ Q50 } & \multicolumn{2}{|l|}{ Q75 } & \multicolumn{2}{|l|}{ Q90 } \\
\hline & $\beta$ & $t$ stat & $\beta$ & $t$ stat & $\beta$ & $t$ stat & $\beta$ & $t$ stat & $\beta$ & $t$ stat \\
\hline \multicolumn{11}{|l|}{ Individual-level characteristics } \\
\hline \multicolumn{11}{|l|}{ Personality traits } \\
\hline r-Emotional stability, FR & 1500 & $(0.34)$ & $6111^{* *}$ & $(2.09)$ & $4203^{*}$ & $(1.89)$ & $6678^{* * *}$ & $(3.11)$ & 2410 & $(0.90)$ \\
\hline r-Extraversion, FR & 2167 & $(0.50)$ & 3108 & $(1.10)$ & 2904 & $(1.33)$ & 3284 & $(1.59)$ & $6016^{*}$ & $(1.90)$ \\
\hline r-Openness, FR & -5676 & $(-1.49)$ & -3441 & $(-1.32)$ & 1939 & $(0.89)$ & 2081 & $(1.04)$ & 2959 & $(1.13)$ \\
\hline r-Agreeableness, FR & 2946 & $(0.66)$ & -1585 & $(-0.58)$ & 884 & $(0.49)$ & -981 & $(-0.51)$ & -460 & $(-0.17)$ \\
\hline r-Conscientiousness, FR & 3180 & $(0.75)$ & 3396 & $(1.29)$ & 1661 & $(0.81)$ & 61 & $(0.03)$ & 1375 & $(0.44)$ \\
\hline r-Emotional stability, NFR & 2791 & $(0.51)$ & 1146 & $(0.36)$ & 832 & $(0.37)$ & $4032^{*}$ & (1.95) & 3864 & $(1.32)$ \\
\hline r-Extraversion, NFR & -6429 & $(-1.46)$ & -1857 & $(-0.70)$ & -880 & $(-0.36)$ & -2300 & $(-1.11)$ & 989 & $(0.38)$ \\
\hline r-Openness, NFR & 2289 & $(0.44)$ & -362 & $(-0.13)$ & 1019 & $(0.54)$ & 1260 & $(0.61)$ & 990 & $(0.35)$ \\
\hline r-Agreeableness, NFR & -575 & $(-0.12)$ & -2406 & $(-0.84)$ & -1107 & $(-0.57)$ & $-3889^{* *}$ & $(-2.00)$ & -3623 & $(-1.18)$ \\
\hline r-Conscientiousness, NFR & 6032 & $(1.24)$ & 3534 & $(1.19)$ & 2558 & $(1.11)$ & 2894 & $(1.34)$ & -888 & $(-0.30)$ \\
\hline Age, FR & $2069^{* *}$ & $(2.57)$ & $1293^{* *}$ & $(2.15)$ & $913^{* * *}$ & $(2.60)$ & $841^{*}$ & $(1.93)$ & -4 & $(-0.01)$ \\
\hline Age, NFR & 561 & $(0.85)$ & 703 & $(1.31)$ & 241 & $(0.55)$ & 21 & $(0.05)$ & $1248^{* * *}$ & $(2.64)$ \\
\hline Age left education, FR & 2280 & $(1.29)$ & $2905^{* *}$ & $(2.34)$ & $2779^{* * *}$ & $(4.16)$ & $2844^{* * *}$ & $(4.42)$ & $2055^{*}$ & (1.93) \\
\hline Age left education, NFR & 1331 & $(0.57)$ & 2429 & $(1.52)$ & $2884^{* * *}$ & $(3.00)$ & $2955^{* * *}$ & $(2.83)$ & $4073^{* * *}$ & (3.16) \\
\hline Delayed word recall, FR & 2412 & $(1.17)$ & $2460^{* *}$ & $(2.10)$ & $1483^{*}$ & $(1.65)$ & 529 & $(0.61)$ & -1050 & $(-0.92)$ \\
\hline Delayed word recall, NFR & 1990 & $(1.18)$ & 1917 & $(1.50)$ & $1317^{*}$ & $(1.75)$ & $1765^{* *}$ & $(2.25)$ & $3305^{* * *}$ & $(2.68)$ \\
\hline \multicolumn{11}{|l|}{ Labour market status } \\
\hline Employed, FR & Ref. & & Ref. & & Ref. & & Ref. & & Ref. & \\
\hline Retired, FR & -9392 & $(-0.67)$ & -163 & $(-0.02)$ & 768 & $(0.18)$ & 3510 & $(0.79)$ & 7282 & $(1.20)$ \\
\hline Other, FR & $-52,644^{* * *}$ & $(-4.60)$ & $-33,547^{* * *}$ & $(-3.76)$ & $-19,198^{* * *}$ & $(-3.55)$ & $-13,471^{* *}$ & $(-2.55)$ & $-16,879^{* *}$ & $(-2.49)$ \\
\hline Employed, FR & Ref. & & Ref. & & Ref. & & Ref. & & Ref. & \\
\hline Retired, NFR & $-11,456$ & $(-0.89)$ & 518 & $(0.08)$ & -3338 & $(-0.62)$ & -1520 & $(-0.26)$ & -5293 & $(-0.72)$ \\
\hline Other, NFR & $-21,430^{*}$ & $(-1.71)$ & -9534 & $(-1.20)$ & -6436 & $(-1.22)$ & -3869 & $(-0.86)$ & -5067 & $(-0.67)$ \\
\hline \multicolumn{11}{|l|}{ SEP in childhood } \\
\hline Well-off family, FR & Ref. & & Ref. & & Ref. & & Ref. & & Ref. & \\
\hline Average family, FR & 5062 & $(0.28)$ & -1618 & $(-0.16)$ & -4029 & $(-0.67)$ & -3913 & $(-0.50)$ & $-14,589$ & $(-1.64)$ \\
\hline Poor family, FR & -6065 & $(-0.31)$ & $-15,772$ & $(-1.35)$ & $-11,456$ & $(-1.64)$ & $-18,028^{* *}$ & $(-2.04)$ & $-24,745^{* *}$ & $(-2.52)$ \\
\hline Well-off family, NFR & Ref. & & Ref. & & Ref. & & Ref. & & Ref. & \\
\hline Average family, NFR & $-17,900$ & $(-1.04)$ & 393 & $(0.05)$ & -9918 & $(-1.23)$ & -7305 & $(-1.33)$ & -6747 & $(-0.77)$ \\
\hline Poor family, NFR & $-24,024$ & $(-1.13)$ & -7473 & $(-0.72)$ & $-18,796^{* *}$ & $(-2.16)$ & $-13,689^{* *}$ & $(-2.09)$ & $-13,345$ & $(-1.30)$ \\
\hline \multicolumn{11}{|l|}{ Household-level characteristics } \\
\hline Number of children & 1495 & $(0.77)$ & -231 & $(-0.18)$ & -946 & $(-0.77)$ & -347 & $(-0.32)$ & -157 & $(-0.10)$ \\
\hline \multicolumn{11}{|l|}{ Location } \\
\hline Dublin & Ref. & & Ref. & & Ref. & & Ref. & & Ref. & \\
\hline Urban outside Dublin & $-22,176$ & $(-1.61)$ & $-41,334^{* * *}$ & $(-5.08)$ & $-41,219^{* * *}$ & $(-7.21)$ & $-47,199^{* * *}$ & $(-10.53)$ & $-38,621^{* * *}$ & $(-4.91)$ \\
\hline Rural & $-11,927$ & $(-1.01)$ & $-38,717^{* * *}$ & $(-5.72)$ & $-47,851^{* * *}$ & $(-10.45)$ & $-45,401^{* * *}$ & $(-9.42)$ & $-36,731^{* * *}$ & $(-6.52)$ \\
\hline Log weekly income & -3258 & $(-0.44)$ & 1894 & $(0.37)$ & -722 & $(-0.35)$ & -543 & $(-0.34)$ & -844 & $(-0.35)$ \\
\hline Constant & $-116,884$ & $(-1.40)$ & $-100,415^{*}$ & $(-1.92)$ & 24,722 & $(0.80)$ & $63,768^{*}$ & $(1.77)$ & 65,372 & $(1.33)$ \\
\hline Pseudo $R^{2}$ & 0.172 & & 0.155 & & 0.181 & & 0.208 & & 0.237 & \\
\hline Personality $\Delta$ Pseudo $R^{2}$ & 0.014 & & 0.012 & & 0.013 & & 0.017 & & 0.020 & \\
\hline$N$ & 1172 & & 1172 & & 1172 & & 1172 & & 1172 & \\
\hline
\end{tabular}

Abbreviations: FR: financial respondent; NFR: non-financial respondent; Ref: reference category; SEP: socio-economic position.

Notes: $t$ statistics in parentheses; ${ }^{*} p<0.10,{ }^{* * *} p<0.05,{ }^{* * *} p<0.01$; bootstrapped standard errors computed. Net housing wealth has been transformed with the inverse hyperbolic sine function. Each of the personality traits has been conditioned on a polynomial in age to net out life cycle influences. The resulting personality trait is based on the standardised residual from this process, i.e. zero mean and unit standard deviation. Personality $\Delta$ Pseudo $R^{2}$ is the difference between the Pseudo $R^{2}$ of the model including all covariates and the Pseudo $R^{2}$ of the model including all covariates except personality traits.

agreeableness $r=0.08$; conscientiousness $r=0.12$ ) with an average effect size of 0.14 . Thus, while we do not dispute the fact that many financial decisions are made by consensus agreement at the couple level, the results would seem to indicate that the traits of the FR predominate. That the effects of personality on wealth are more important for the FR compared with the NFR is an important finding as it suggests that intervention strategies designed to incentivise saving/provision for retirement should target the FR.

\subsection{Emotional stability and wealth}

Emotional stability of the FR was found to be positively associated with wealth controlling for the personality characteristics of the NFR (Table 3). The relationship was only significant at and above the 50th quantile of the conditional wealth distribution. The decomposition analysis, which considered the impact of personality characteristics of the FR (Table 4, Panel 1) and NFR (Table 4, Panel 2) independently of each other, found that emotional stability of the NFR was associated with net wealth but these associations were rendered non-significant when adjusted for the personality characteristics of the FR (Table 3). When we decomposed net wealth into net housing wealth and net non-housing wealth, we found that emotional 
Quantile regression results for (transformed) net non-housing wealth.

\begin{tabular}{|c|c|c|c|c|c|c|c|c|c|c|}
\hline & \multicolumn{2}{|l|}{$\underline{Q} 10$} & \multicolumn{2}{|l|}{ Q25 } & \multicolumn{2}{|l|}{$\underline{Q 50}$} & \multicolumn{2}{|l|}{ Q75 } & \multicolumn{2}{|l|}{ Q90 } \\
\hline & $\beta$ & $t$ stat & $\beta$ & $t$ stat & $\beta$ & $t$ stat & $\beta$ & $t$ stat & $\beta$ & $t$ stat \\
\hline \multicolumn{11}{|l|}{ Individual-level characteristics } \\
\hline \multicolumn{11}{|l|}{ Personality traits } \\
\hline r-Emotional stability, FR & 818 & $(0.64)$ & 1609 & $(0.99)$ & 2665 & $(0.69)$ & 4220 & $(0.86)$ & $10,336^{*}$ & $(1.69)$ \\
\hline r-Extraversion, FR & 566 & $(0.38)$ & $2534^{*}$ & $(1.71)$ & 3210 & $(0.85)$ & 5898 & $(1.10)$ & 5875 & $(1.16)$ \\
\hline r-Openness, FR & -1515 & $(-1.16)$ & $-4468^{* *}$ & $(-2.28)$ & -2629 & $(-0.74)$ & -7666 & $(-1.33)$ & $-11,749^{*}$ & $(-1.90)$ \\
\hline r-Agreeableness, FR & -1151 & $(-0.98)$ & -1001 & $(-0.78)$ & $-6936^{* *}$ & $(-2.08)$ & -6967 & $(-1.53)$ & -3628 & $(-0.59)$ \\
\hline r-Conscientiousness, FR & $2261^{* *}$ & $(2.01)$ & $3444^{* *}$ & $(2.11)$ & 2918 & $(0.83)$ & 7076 & $(1.49)$ & 1429 & $(0.22)$ \\
\hline r-Emotional stability, NFR & 1603 & $(1.07)$ & 416 & $(0.25)$ & -1819 & $(-0.50)$ & 884 & $(0.16)$ & 4118 & $(0.77)$ \\
\hline r-Extraversion, NFR & 438 & $(0.32)$ & -884 & $(-0.43)$ & 1870 & $(0.56)$ & 1427 & $(0.25)$ & -6210 & $(-0.86)$ \\
\hline r-Openness, NFR & -120 & $(-0.06)$ & -590 & $(-0.30)$ & -601 & $(-0.16)$ & -3930 & $(-0.74)$ & 1325 & $(0.15)$ \\
\hline r-Agreeableness, NFR & 154 & $(0.12)$ & 456 & $(0.28)$ & -1571 & $(-0.39)$ & 1409 & $(0.29)$ & 7625 & $(1.21)$ \\
\hline r-Conscientiousness, NFR & -2455 & $(-1.63)$ & -101 & $(-0.06)$ & 2140 & $(0.62)$ & 1635 & $(0.24)$ & 2767 & $(0.52)$ \\
\hline Age, FR & -30 & $(-0.11)$ & 155 & $(0.47)$ & 615 & $(0.77)$ & $2226^{* *}$ & $(2.06)$ & 1650 & $(0.99)$ \\
\hline Age, NFR & 367 & $(1.54)$ & 446 & $(1.64)$ & 208 & $(0.30)$ & -499 & $(-0.46)$ & -527 & $(-0.39)$ \\
\hline Age left education, FR & -324 & $(-0.49)$ & $1662^{*}$ & $(1.65)$ & $6382^{* * *}$ & $(4.08)$ & $10,608^{* * *}$ & $(5.30)$ & $10,866^{* * *}$ & $(4.11)$ \\
\hline Age left education, NFR & 877 & $(1.28)$ & $2479^{* * *}$ & $(3.02)$ & $3180^{* *}$ & $(2.03)$ & $3593^{*}$ & $(1.67)$ & 3155 & $(1.18)$ \\
\hline Delayed word recall, FR & -437 & $(-0.76)$ & -904 & $(-1.16)$ & -2001 & $(-1.25)$ & -1233 & $(-0.57)$ & $-4238^{*}$ & $(-1.67)$ \\
\hline Delayed word recall, NFR & 3 & $(0.01)$ & -315 & $(-0.45)$ & 381 & $(0.26)$ & 1181 & $(0.60)$ & -741 & $(-0.26)$ \\
\hline \multicolumn{11}{|l|}{ Labour market status } \\
\hline Employed, FR & Ref. & & Ref. & & Ref. & & Ref. & & Ref. & \\
\hline Retired, FR & 3903 & $(0.89)$ & 3490 & $(0.77)$ & 11,863 & $(1.03)$ & $-18,146$ & $(-1.28)$ & $-25,344$ & $(-1.41)$ \\
\hline Other, FR & -2795 & $(-0.76)$ & $-8212^{* *}$ & $(-2.03)$ & $-15,859$ & $(-1.54)$ & $-43,865^{* * *}$ & $(-2.96)$ & $-48,990^{* * *}$ & $(-3.29)$ \\
\hline Employed, FR & Ref. & & Ref. & & Ref. & & Ref. & & Ref. & \\
\hline Retired, NFR & $-5953^{*}$ & $(-1.76)$ & $-8659 *$ & $(-1.91)$ & $-27,202^{* *}$ & $(-2.54)$ & $-35,237^{* *}$ & $(-2.33)$ & $-45,646^{* * *}$ & $(-2.83)$ \\
\hline Other, NFR & $-7429^{* *}$ & $(-2.22)$ & $-10,544^{* *}$ & $(-2.50)$ & $-38,225^{* * *}$ & $(-4.20)$ & $-54,317^{* * *}$ & $(-3.91)$ & $-75,686^{* * *}$ & $(-4.93)$ \\
\hline \multicolumn{11}{|l|}{ SEP in childhood } \\
\hline Well-off family, FR & Ref. & & Ref. & & Ref. & & Ref. & & Ref. & \\
\hline Average family, FR & -1034 & $(-0.20)$ & -1163 & $(-0.19)$ & $-17,322$ & $(-1.22)$ & $-41,536^{* *}$ & $(-2.06)$ & $-55,997^{* * *}$ & $(-2.73)$ \\
\hline Poor family, FR & -5800 & $(-0.95)$ & -2981 & $(-0.40)$ & $-23,063$ & $(-1.40)$ & $-51,630^{* *}$ & $(-2.23)$ & $-62,836^{* *}$ & $(-2.50)$ \\
\hline Well-off family, NFR & Ref. & & Ref. & & Ref. & & Ref. & & Ref. & \\
\hline Average family, NFR & -8978 & $(-1.62)$ & $-14,860$ & $(-1.53)$ & $-45,140^{* * *}$ & $(-2.78)$ & $-41,214^{* *}$ & $(-2.16)$ & $-29,197$ & $(-1.50)$ \\
\hline Poor family, NFR & -9026 & $(-1.55)$ & $-14,062$ & $(-1.40)$ & $-49,657^{* * *}$ & $(-2.88)$ & $-51,874^{* *}$ & $(-2.49)$ & $-63,532^{* * *}$ & $(-3.02)$ \\
\hline \multicolumn{11}{|l|}{ Household-level characteristics } \\
\hline Number of children & -506 & $(-0.73)$ & -1113 & $(-1.21)$ & -1679 & $(-0.93)$ & -1026 & $(-0.40)$ & 661 & $(0.20)$ \\
\hline \multicolumn{11}{|l|}{ Location } \\
\hline Dublin & Ref. & & Ref. & & Ref. & & Ref. & & Ref. & \\
\hline Urban outside Dublin & -175 & $(-0.04)$ & $-7434^{*}$ & $(-1.86)$ & $-21,316^{* *}$ & $(-2.41)$ & $-15,780$ & $(-1.31)$ & $-27,446^{* *}$ & $(-2.13)$ \\
\hline Rural & -2842 & $(-0.83)$ & $-7602^{*}$ & $(-1.81)$ & -682 & $(-0.07)$ & $28,078^{* *}$ & $(2.26)$ & 23,501 & $(1.44)$ \\
\hline Log weekly income & 698 & $(0.24)$ & 3436 & $(1.23)$ & 2199 & $(0.45)$ & -1428 & $(-0.32)$ & -8954 & $(-1.22)$ \\
\hline Constant & $-11,475$ & $(-0.41)$ & $-69,743^{* *}$ & $(-2.18)$ & $-59,423$ & $(-0.97)$ & $-79,929$ & $(-0.99)$ & 131,040 & $(0.93)$ \\
\hline Pseudo $R^{2}$ & 0.023 & & 0.054 & & 0.105 & & 0.153 & & 0.180 & \\
\hline Personality $\Delta$ Pseudo $R^{2}$ & 0.007 & & 0.007 & & 0.006 & & 0.013 & & 0.021 & \\
\hline$N$ & 1172 & & 1172 & & 1172 & & 1172 & & 1172 & \\
\hline
\end{tabular}

Abbreviations: FR: financial respondent; NFR: non-financial respondent; Ref: reference category; SEP: socio-economic position.

Notes: $t$ statistics in parentheses; ${ }^{*} p<0.10,{ }^{* *} p<0.05,{ }^{* * *} p<0.01$; bootstrapped standard errors computed. Net non-housing wealth has been transformed with the inverse hyperbolic sine function. Each of the personality traits has been conditioned on a polynomial in age to net out life cycle influences. The resulting personality trait is based on the standardised residual from this process, i.e. zero mean and unit standard deviation. Personality $\Delta$ Pseudo $R^{2}$ is the difference between the Pseudo $R^{2}$ of the model including all covariates and the Pseudo $R^{2}$ of the model including all covariates except personality traits.

stability was significantly associated with net housing wealth for the FR at the 25th, 50th and 75th quantiles of the distribution (Table 5). By contrast, emotional stability of the FR was only significantly associated with net non-housing health at the 90th percentile of the conditional distribution (Table 6).

But what are the life-course pathways through which this personality trait contributes to wealth? One obvious line of reasoning is that individuals who are emotionally stable are more successful in the labour market where such characteristics are likely to be rewarded with higher remuneration and increased promotional opportunities. Consistent with such a proposition, prospective studies have found that emotional stability is positively correlated with intrinsic career satisfaction measures, and extrinsic career success measures including occupational attainment and earnings (Gelissen \& de Graaf, 2006; Judge \& Bono, 2001; Judge, Higgins, Thoresen, \& Barrick, 1999; Sutin, Costa, Miech, \& Eaton, 2009).

Alternatively it could be that more emotionally stable people make better informed financial decisions. Interestingly, laboratory-based studies of financial risk taking have shown that individuals who are more emotionally stable take more risks to achieve a gain (Lauriola \& Levin, 2001), whereas trait-anxious individuals (i.e. low in emotional stability) tend to over-estimate risk (Butler \& Mathews, 1987) which motivates a preference for loss avoidance. A recent genetic study found that individuals with the short allele of a genetic polymorphism in the promoter region of the serotonin transporter gene 
(which is linked to neuroticism) invested less in equities and were less engaged in making financial decisions compared with those with the long/long or short/long versions of the genotype. These preferences were not due to underlying differences in education, cognition, wealth, or the ability to learn on a financial learning task (Kuhnen, Samanez-Larkin, \& Knutson, 2013): a finding which lends credence to the idea that these innate individual differences in dispositional characteristics are causally related to later life wealth accumulation.

Finally, recognising that many financial decisions are taken at the household level, it could be argued that high emotional stability in the FR may moderate the spending preferences of the NFR, all other things being equal. Indeed, there is even some evidence that individuals in couple pairs with spendthrift tendencies are more likely to select a partner with thrifty tendencies to help balance the relationship (Rick, Small, \& Finkel, 2011). Future research should try to empirically test and decompose these different pathways.

\subsection{Conscientiousness and wealth}

In accordance with our predictions and the results of some previous studies (Davey \& George, 2010; Duckworth \& Weir, 2010), conscientiousness was positively associated with net wealth net of other demographic and human capital variables. It is worth recalling that this personality trait measures a constellation of characteristics that are associated with forward planning and future orientation, including self-discipline and restraint. An important qualification however is that conscientiousness only significantly predicted net wealth at the 10th quantile of the conditional wealth distribution. Interestingly, we also observed significant effects of conscientiousness at the lower end of the wealth distribution when the personality characteristics of the FR and the NFR were averaged (Table 4, Panel 3), which suggests that conscientiousness may have multiplicative effects among couples who are similar in this respect. The decomposition analysis revealed that conscientiousness of the FR was significantly associated with non-housing wealth (Table A3) but not housing wealth (Table A2). It should be acknowledged that other studies have arrived at mixed findings regarding the effects of conscientiousness on wealth. Nyhus and Webley (2001) found that conscientiousness was unrelated to savings or borrowings, and Brown and Taylor (2014) found that this trait was unrelated to the value of assets held. Duckworth \& Weir by contrast documented clear associations between conscientiousness and wealth in the US HRS study (2010). One possible explanation for the finding that conscientiousness seems to matter more at the lower end of the wealth distribution is that households have to be more discerning about their consumption pattern when resources are scarce compared to when resources are plentiful. Under these circumstances, conscientiousness may be particularly important because a higher level of acquired wealth provides a buffer against potential future financial shocks. Nevertheless, it would be useful to try to replicate this finding in other populations.

\subsection{Extraversion and wealth}

Extraversion was found to be positively associated with wealth accumulation and was statistically significant at the 50th and 75th quantile of the conditional distribution (Table 3). This result runs contrary to our predictions and is at odds with the results of other studies which have found that extraversion is negatively associated with savings (Davey \& George, 2010; Nyhus \& Webley, 2001). Although speculative, one potential explanation for this rather counter-intuitive finding is that extraversion may be differentially rewarded in the Irish context, which may translate into higher wages across productive years in the labour market. Previous studies have arrived at inconsistent conclusions regarding whether extraversion is rewarded in the workplace with the study by Nyhus and Pons (2005) reporting no significant returns to earnings, while a separate study involving a Finnish cohort found that extraversion measured at 8 years, and 42 years of age was positively associated with earnings (Viinikainen, Kokko, Pulkkinen, \& Pehkonen, 2010). While these studies were looking at the effects of personality on wages rather than wealth, it is reasonable to assume the income from work and wealth are positively associated.

\subsection{Openness to experience and wealth}

An interesting trend that was apparent in the data was the negative correlation between wealth and openness to experience. Although none of the associations were statistically significant, there was a general tendency for openness to be inversely associated with net wealth. On first inspection, this appears a counter-intuitive finding as openness is correlated with intelligence and we predicted that this might lead to higher earnings over the lifetime and more prudent financial decision making. However, the facets of this trait include curiosity, imagination, and enjoyment of novelty which may cause individuals high on this trait to consume more in later life (e.g. international travel).

\subsection{Agreeableness and wealth}

There were no significant relationships between agreeableness and wealth even though the observed associations were generally negative. Studies have previously shown that participants who score high in agreeableness tend to have lower income earnings (Heineck, 2011; Mueller \& Plug, 2006) so this may help explain the negative relationship between agreeableness and wealth over time. 


\subsection{Limitations}

The study has a number of limitations. Firstly, personality traits were measured at the same time as the dependent variable so reverse causality remains a concern. We argued in the introduction that there are good reasons for treating personality as an exogenous variable that is causal to wealth accumulation. However, a recent study which used lottery winners as an instrument found that a change in unearned income (i.e. lottery win) was associated with changes in some personality traits (Powdthavee, Boyce, \& Wood, 2011). Secondly, we had a substantial number of couple pairs who were excluded from the analysis because: (a) one of the persons within the couple pair did not participate in TILDA, or (b) they were missing information on wealth. We attempted to overcome the second problem by inputing for missing cases where wealth was missing, and these sensitivity analyses revealed that the trends in the data were very similar. Thirdly, there is little portfolio diversification in Ireland and the majority of Irish people's wealth is bound up in the asset value of their residential property which limits our ability to look at individual components of wealth such as savings and financial investments. It is important to note that Ireland experienced a huge macro-economic shock between 2007 and 2013 as a consequence of the Great Recession with house prices declining by $57.4 \%$ in Dublin and by $48.7 \%$ in the rest of the country (Kitchin, Hearne, \& O'Callaghan, 2015). The Irish lost more of their personal wealth per capita between 2009 and 2013 than any other Euro-zone country (European Central Bank, 2015). The baseline survey year for the TILDA study was $2009 / 2010$ so it is likely that a lot of these losses had already accrued by the time the data was collected. This latter caveat also means that results may not hold in other countries or jurisdictions that have a lower level of home ownership compared with Ireland.

Fourthly, pension wealth is not included among our measures of wealth. This is problematic to the extent that it may cause us to underestimate the effects of conscientiousness on wealth if conscientious individuals are more likely to hold a pension, and/or the value of that pension is higher on average than those who score lower on this trait. Determining pension wealth among older couples, some of whom are retired, and some of whom are still contributing to occupational pensions is a non-trivial exercise. In addition, previous research has shown that 'pension-related knowledge' is very poor even among those who are approaching retirement. For example, in Ireland two-thirds of individuals aged 50+ and enrolled in pension schemes do not know what amount will be paid out on retirement and/or whether the payments will be in the form of lump sums, monthly payments, or both (Barrett, Mosca, \& Whelan, 2015). Finally, it is entirely plausible that these results may not hold in other cultural contexts because of differences in welfare systems that may differentially incentivise or disincentivise savings behaviour, or because of differences in how these personality traits are rewarded and reinforced within countries (Hofstede \& McCrae, 2004). For example, as the recent worldwide financial crisis has shown, some countries naturally value prudence in fiscal matters whereas other countries may adopt or encourage financial investment and risktaking.

\subsection{Strengths}

The study also has a number of strengths. It employs a gold standard measure of personality in the context of a large epidemiological study which yields fairly robust measures of dispositional tendencies and preferences. We were also able to control for a wide range of covariates that could possibly conflate the association between personality and wealth such as childhood socio-economic position, which may contribute to wealth via inheritance. Finally, it examines the putative causal role of personality on wealth accumulation by focusing on the financial dynamic within the household (i.e. FR versus NFR) rather than stratifying by gender as others have done (e.g. Duckworth \& Weir, 2010), and finding that the personality characteristics of the FR matter more.

\subsection{Conclusions and policy implications}

Overall, our empirical findings indicate that personality is important in shaping individuals' economic and financial decision-making. Our paper contributes to the limited but expanding literature exploring the implications of personality traits for economic outcomes in later life among older couples. Our results have the potential to not only enhance our understanding of economic decision making within couples, but also to expand the spectrum of policy options that could be used to assist households to have adequate resources in retirement. It is becoming increasingly clear that Government messages simply telling people to save more for their retirement is not sufficient to change behaviour.

In essence, this comes down to whether Governments should 'shove' or 'nudge' people to provide more for their retirement (c.f. Chetty, Friedman, Leth-Petersen, Nielsen, \& Olsen, 2012). One potential solution is to completely ignore individual differences in the propensity to save and force individuals (i.e. shove) to provide more for retirement through automatic (mandatory) enrolment in a pension scheme (e.g. Australia's superannuation scheme). However, in designing such schemes, one has to give consideration to unintended consequences. It is entirely plausible that in doing so, Governments may actually disincentivise additional savings for retirement if individuals assume that the contributions made through automatic enrolment equate to a comfortable retirement (Hardcastle, 2012). What is needed is a well designed series of behavioural 'nudges' or choice architectures that leverage individual differences in dispositional tendencies and natural preferences to incentivise saving for retirement. A good example is the Save More Tomorrow (SMART) scheme (Thaler \& Benartzi, 2004) which recognises that people consider immediate losses to be more important than future gains. They therefore designed a scheme 
which allowed employees to increase their future savings rate when they got their next pay rise and thus would not suffer any immediate loss of income. They found that this scheme increased participants' retirement savings rate from $3.5 \%$ to $13.6 \%$ in just 3.5 years.

There are few concrete examples of how we can nudge people with different personality traits to increase savings for retirement as behavioural economics is still in its infancy but it may still be possible. For example, tax incentive schemes that provide tax relief for individuals making additional voluntary contributions might be a useful economic lever for conscientious individuals. Agreeable individuals by contrast may be more likely to respond to prevailing social norms, and there is some evidence that normative messages may be effective in eliciting behavioural change among individuals. For example, Schultz, Khazian, and Zaleski (2008) found that a simple message informing hotel guests that $75 \%$ of individuals reused their towel was effective in encouraging conservation among hotel guests. Future studies should be designed to ascertain whether these behavioural insights and techniques are effective in promoting, incentivising and sustaining the savings rate among individuals with different personality traits.

\section{Acknowledgements}

Funding for this work was provided by a Health Research Board of Ireland grant (ICE/2011/7) under the Inter-disciplinary Capacity Enhancement Programme. Funding for the TILDA study is provided by the Irish Government, The Atlantic Philanthropies, and Irish Life plc.

\section{Appendix A}

See Tables A1-A3.

Table A1

Quantile regression results for (transformed) net wealth. Observations where one or more components of net wealth have been imputed are included.

\begin{tabular}{|c|c|c|c|c|c|c|c|c|c|c|}
\hline & \multicolumn{2}{|l|}{ Q10 } & \multicolumn{2}{|l|}{ Q25 } & \multicolumn{2}{|l|}{ Q50 } & \multicolumn{2}{|l|}{ Q75 } & \multicolumn{2}{|l|}{ Q90 } \\
\hline & $\beta$ & $t$ stat & $\beta$ & $t$ stat & $\beta$ & $t$ stat & $\beta$ & $t$ stat & $\beta$ & $t$ stat \\
\hline \multicolumn{11}{|l|}{ Individual-level characteristics } \\
\hline \multicolumn{11}{|l|}{ Personality traits } \\
\hline r-Emotional stability, FR & $7395^{*}$ & (1.79) & $5976^{*}$ & $(1.96)$ & 2708 & $(1.16)$ & 4548 & $(1.59)$ & $8808^{* *}$ & $(2.01)$ \\
\hline r-Extraversion, FR & 3568 & $(0.93)$ & 3401 & $(1.52)$ & $6397^{* * *}$ & $(2.83)$ & $4767^{*}$ & $(1.78)$ & $9812^{* *}$ & $(2.49)$ \\
\hline r-Openness, FR & -4856 & $(-1.45)$ & -1886 & $(-0.66)$ & -2391 & $(-1.02)$ & -3187 & $(-1.39)$ & -4746 & $(-1.05)$ \\
\hline r-Agreeableness, FR & $-5782^{*}$ & $(-1.66)$ & -2184 & $(-1.02)$ & -330 & $(-0.13)$ & -1522 & $(-0.48)$ & -1708 & $(-0.44)$ \\
\hline r-Conscientiousness, FR & $10,745^{* *}$ & $(2.41)$ & $5985^{* *}$ & $(2.50)$ & $4049^{*}$ & $(1.67)$ & 3296 & $(1.17)$ & 1313 & $(0.33)$ \\
\hline r-Emotional stability, NFR & 3925 & $(0.79)$ & 2616 & $(0.96)$ & 3397 & (1.39) & $4316^{* *}$ & $(2.09)$ & 4583 & $(1.50)$ \\
\hline r-Extraversion, NFR & -1892 & $(-0.48)$ & -1400 & $(-0.48)$ & -1796 & $(-0.70)$ & 1068 & $(0.40)$ & -48 & $(-0.01)$ \\
\hline r-Openness, NFR & -1444 & $(-0.36)$ & 1122 & $(0.41)$ & 2232 & $(0.92)$ & -11 & $(-0.00)$ & 2837 & $(0.71)$ \\
\hline r-Agreeableness, NFR & 1410 & $(0.31)$ & $-4316^{*}$ & $(-1.76)$ & -3242 & $(-1.60)$ & -3066 & $(-1.10)$ & -7389 & $(-1.53)$ \\
\hline r-Conscientiousness, NFR & 3714 & $(0.62)$ & 2789 & $(1.13)$ & 2390 & $(0.87)$ & 1745 & $(0.67)$ & 5527 & $(1.44)$ \\
\hline Age, FR & 961 & $(1.24)$ & $1466^{* * *}$ & (2.69) & $886^{*}$ & $(1.75)$ & $969^{*}$ & $(1.91)$ & $1515^{* *}$ & $(2.12)$ \\
\hline Age, NFR & 460 & $(0.67)$ & -54 & $(-0.10)$ & 90 & $(0.18)$ & 132 & $(0.23)$ & -392 & $(-0.51)$ \\
\hline Age left education, FR & 2655 & $(1.51)$ & $4424^{* * *}$ & $(4.33)$ & $4242^{* * *}$ & $(4.96)$ & $4975^{* * *}$ & $(4.76)$ & $6395^{* * *}$ & $(3.58)$ \\
\hline Age left education, NFR & 2398 & (1.27) & $3566^{* *}$ & $(2.54)$ & $3467^{* * *}$ & (3.44) & $4268^{* * *}$ & $(4.34)$ & $4042^{* * *}$ & $(2.83)$ \\
\hline Delayed word recall, FR & 1240 & $(0.68)$ & 543 & $(0.57)$ & 72 & $(0.07)$ & -337 & $(-0.30)$ & $-3560^{*}$ & $(-1.83)$ \\
\hline Delayed word recall, NFR & 1047 & $(0.65)$ & $1675^{*}$ & $(1.72)$ & 1132 & (1.13) & 1154 & $(1.19)$ & 2089 & $(1.12)$ \\
\hline \multicolumn{11}{|l|}{ Labour market status } \\
\hline Employed, FR & Ref. & & Ref. & & Ref. & & Ref. & & Ref. & \\
\hline Retired, FR & 14,750 & $(1.58)$ & 9060 & $(1.29)$ & 4478 & $(0.71)$ & -3404 & $(-0.49)$ & -6199 & $(-0.60)$ \\
\hline Other, FR & $-36,568^{* * *}$ & $(-2.93)$ & $-23,580^{* * *}$ & $(-3.09)$ & $-23,901^{* * *}$ & $(-3.39)$ & $-29,118^{* * *}$ & $(-4.09)$ & $-31,722^{* * *}$ & $(-3.13)$ \\
\hline Employed, FR & Ref. & & Ref. & & Ref. & & Ref. & & Ref. & \\
\hline Retired, NFR & -7563 & $(-0.71)$ & $-12,416^{*}$ & $(-1.91)$ & $-12,259^{* *}$ & $(-2.02)$ & $-18,181^{* * *}$ & $(-2.59)$ & $-33,982^{* * *}$ & $(-3.10)$ \\
\hline Other, NFR & $-24,335^{* *}$ & $(-2.19)$ & $-19,338^{* * *}$ & $(-2.86)$ & $-20,397^{* * *}$ & $(-3.37)$ & $-27,824^{* * *}$ & $(-3.99)$ & $-51,791^{* * *}$ & $(-5.32)$ \\
\hline \multicolumn{11}{|l|}{ SEP in childhood } \\
\hline Well-off family, FR & Ref. & & Ref. & & Ref. & & Ref. & & Ref. & \\
\hline Average family, FR & 585 & $(0.04)$ & -6185 & $(-0.81)$ & -6850 & $(-1.01)$ & $-21,995^{* *}$ & $(-2.18)$ & $-25,785$ & $(-1.64)$ \\
\hline Poor family, FR & $-17,090$ & $(-0.94)$ & $-25,363^{* * *}$ & $(-3.13)$ & $-25,169^{* * *}$ & $(-2.76)$ & $-29,837^{* * *}$ & $(-3.05)$ & $-36,596^{* *}$ & $(-2.28)$ \\
\hline Well-off family, NFR & Ref. & & Ref. & & Ref. & & Ref. & & Ref. & \\
\hline Average family, NFR & $-29,368^{* *}$ & $(-2.43)$ & $-15,461^{* *}$ & $(-2.02)$ & $-17,902^{* *}$ & $(-2.51)$ & $-11,203$ & $(-1.54)$ & -2717 & $(-0.21)$ \\
\hline Poor family, NFR & $-25,872^{*}$ & $(-1.77)$ & $-24,008^{* * *}$ & $(-2.72)$ & $-28,063^{* * *}$ & $(-3.14)$ & $-25,079^{* * *}$ & $(-3.06)$ & $-16,556$ & $(-1.30)$ \\
\hline \multicolumn{11}{|l|}{ Household-level characteristics } \\
\hline Number of children & 2372 & $(1.38)$ & -829 & $(-0.70)$ & -982 & $(-0.72)$ & 1186 & $(1.01)$ & 2560 & $(1.21)$ \\
\hline \multicolumn{11}{|l|}{ Location } \\
\hline Dublin & Ref. & & Ref. & & Ref. & & Ref. & & Ref. & \\
\hline Urban outside Dublin & $-16,296$ & $(-1.42)$ & $-34,482^{* * *}$ & $(-4.60)$ & $-35,114^{* * *}$ & $(-5.72)$ & $-34,968^{* * *}$ & $(-6.22)$ & $-39,593^{* * *}$ & $(-4.07)$ \\
\hline Rural & -7949 & $(-0.73)$ & $-28,956^{* * *}$ & $(-4.79)$ & $-28,994^{* * *}$ & $(-6.01)$ & $-22,004^{* * *}$ & $(-3.77)$ & $-12,682$ & $(-1.21)$ \\
\hline
\end{tabular}


Table A1 (continued)

\begin{tabular}{|c|c|c|c|c|c|c|c|c|c|c|}
\hline & \multicolumn{2}{|l|}{ Q10 } & \multicolumn{2}{|l|}{$\mathrm{Q} 25$} & \multicolumn{2}{|l|}{ Q50 } & \multicolumn{2}{|l|}{ Q75 } & \multicolumn{2}{|l|}{ Q90 } \\
\hline & $\beta$ & $t$ stat & $\beta$ & $t$ stat & $\beta$ & $t$ stat & $\beta$ & $t$ stat & $\beta$ & $t$ stat \\
\hline Log weekly income & $13,745^{* *}$ & $(2.29)$ & 4046 & $(0.99)$ & -556 & $(-0.30)$ & -2346 & $(-0.77)$ & -2827 & $(-0.61)$ \\
\hline Constant & $-143,276^{* *}$ & $(-2.01)$ & $-60,448$ & $(-1.41)$ & 52,559 & $(1.42)$ & $81,273^{* *}$ & $(2.12)$ & 119,152 & $(1.56)$ \\
\hline Pseudo $R^{2}$ & 0.155 & & 0.146 & & 0.141 & & 0.161 & & 0.167 & \\
\hline Personality $\Delta$ Pseudo $R^{2}$ & 0.019 & & 0.012 & & 0.013 & & 0.014 & & 0.025 & \\
\hline$N$ & 1532 & & 1532 & & 1532 & & 1532 & & 1532 & \\
\hline
\end{tabular}

Abbreviations: FR: financial respondent; NFR: non-financial respondent; Ref: reference category; SEP: socio-economic position.

Notes: $t$ statistics in parentheses; ${ }^{*} p<0.10,{ }^{* *} p<0.05,{ }^{* * *} p<0.01$; bootstrapped standard errors computed. Net wealth has been transformed with the inverse hyperbolic sine function. Each of the personality traits has been conditioned on a polynomial in age to net out life cycle influences. The resulting personality trait is based on the standardised residual from this process, i.e. zero mean and unit standard deviation. Personality $\Delta$ Pseudo $R^{2}$ is the difference between the Pseudo $R^{2}$ of the model including all covariates and the Pseudo $R^{2}$ of the model including all covariates except personality traits.

Table A2

Quantile regression results for (transformed) net housing wealth controlling for: personality traits of FR only (Panel1); personality traits of NFR only (Panel 2); averaged personality traits of FR and NFR (Panel 3).

\begin{tabular}{|c|c|c|c|c|c|c|c|c|c|c|}
\hline & \multicolumn{2}{|l|}{ Q10 } & \multicolumn{2}{|l|}{ Q25 } & \multicolumn{2}{|l|}{ Q50 } & \multicolumn{2}{|l|}{ Q75 } & \multicolumn{2}{|l|}{ Q90 } \\
\hline & $\beta$ & t stat & $\beta$ & t stat & $\beta$ & t stat & $\beta$ & t stat & $\beta$ & t stat \\
\hline \multicolumn{11}{|c|}{ Panel 1: personality traits of FR only } \\
\hline r-Emotional stability, FR & 3990 & $(0.93)$ & $5727^{*}$ & $(1.77)$ & $4002^{* *}$ & $(2.07)$ & $6265^{* * *}$ & $(3.44)$ & 3409 & $(1.14)$ \\
\hline r-Extraversion, FR & 2091 & $(0.55)$ & 1094 & $(0.35)$ & 2480 & $(1.15)$ & 2876 & $(1.50)$ & $6880^{*}$ & $(1.84)$ \\
\hline r-Openness, FR & -6859 & $(-1.33)$ & -2805 & $(-1.09)$ & 1261 & $(0.66)$ & 2830 & $(1.56)$ & $4972^{* *}$ & $(2.07)$ \\
\hline r-Agreeableness, FR & 494 & $(0.11)$ & -2064 & $(-0.68)$ & 1225 & $(0.62)$ & -1602 & $(-0.77)$ & -728 & $(-0.29)$ \\
\hline r-Conscientiousness, FR & 1203 & $(0.26)$ & 5305 & $(1.52)$ & 3161 & $(1.53)$ & -103 & $(-0.05)$ & 241 & $(0.08)$ \\
\hline Pseudo $R^{2}$ & 0.138 & & 0.138 & & 0.171 & & 0.198 & & 0.223 & \\
\hline Personality $\Delta$ Pseudo $R^{2}$ & 0.007 & & 0.009 & & 0.009 & & 0.013 & & 0.016 & \\
\hline \multicolumn{11}{|c|}{ Panel 2: personality traits of NFR only } \\
\hline r-Emotional stability, NFR & 5823 & $(1.01)$ & 4141 & $(1.12)$ & 1685 & $(0.91)$ & $3334^{*}$ & $(1.67)$ & 3404 & $(1.34)$ \\
\hline r-Extraversion, NFR & -5389 & $(-1.12)$ & -288 & $(-0.10)$ & -671 & $(-0.24)$ & -689 & $(-0.36)$ & 2221 & $(0.77)$ \\
\hline r-Openness, NFR & 4656 & $(0.90)$ & 1283 & $(0.42)$ & 2157 & $(1.19)$ & 1748 & $(0.86)$ & 2609 & $(1.22)$ \\
\hline r-Agreeableness, NFR & 280 & $(0.05)$ & -3267 & $(-1.31)$ & -1014 & $(-0.50)$ & -2685 & $(-1.42)$ & -3068 & $(-1.03)$ \\
\hline r-Conscientiousness, NFR & 6336 & $(1.13)$ & 4120 & $(1.29)$ & 1593 & $(0.60)$ & 1089 & $(0.48)$ & 1519 & $(0.54)$ \\
\hline Pseudo $R^{2}$ & 0.139 & & 0.133 & & 0.164 & & 0.189 & & 0.215 & \\
\hline Personality $\Delta$ Pseudo $R^{2}$ & 0.008 & & 0.005 & & 0.002 & & 0.004 & & 0.007 & \\
\hline \multicolumn{11}{|c|}{ Panel 3: personality traits of FR and NFR (averaged) } \\
\hline Emotional stability, FR\&NFR & 7259 & $(1.15)$ & $6461^{* *}$ & $(2.17)$ & $4062^{* *}$ & $(2.11)$ & $6511^{* * *}$ & $(3.06)$ & 4918 & $(1.53)$ \\
\hline Extraversion, FR\&NFR & -5249 & $(-1.11)$ & -68 & $(-0.03)$ & 1600 & $(0.69)$ & $2798^{*}$ & $(1.77)$ & 3609 & $(1.27)$ \\
\hline Openness, FR\&NFR & -394 & $(-0.09)$ & -2471 & $(-0.82)$ & 2942 & $(1.57)$ & $3942^{* *}$ & $(2.28)$ & 3555 & $(1.55)$ \\
\hline Agreeableness, FR\&NFR & -1810 & $(-0.49)$ & -4246 & $(-1.64)$ & -60 & $(-0.03)$ & $-3676^{*}$ & $(-1.90)$ & -3755 & $(-1.34)$ \\
\hline Conscientiousness, FR\&NFR & $10,689^{* *}$ & $(2.14)$ & $6740^{* *}$ & $(2.34)$ & 1909 & $(0.87)$ & 903 & $(0.36)$ & 1322 & $(0.39)$ \\
\hline Pseudo $R^{2}$ & 0.141 & & 0.139 & & 0.170 & & 0.199 & & 0.225 & \\
\hline Personality $\Delta$ Pseudo $R^{2}$ & 0.009 & & 0.010 & & 0.007 & & 0.014 & & 0.018 & \\
\hline$N$ & 1172 & & 1172 & & 1172 & & 1172 & & 1172 & \\
\hline
\end{tabular}

Abbreviations: FR: financial respondent; NFR: non-financial respondent.

Notes: $t$ statistics in parentheses; ${ }^{*} p<0.10,{ }^{* *} p<0.05,{ }^{* * *} p<0.01$; bootstrapped standard errors computed. Net housing wealth has been transformed with the inverse hyperbolic sine function. Each of the personality traits has been conditioned on a polynomial in age to net out life cycle influences. The resulting personality trait is based on the standardised residual from this process, i.e. zero mean and unit standard deviation. The controls listed in Section 2.3 .3 were also included. Personality $\Delta$ Pseudo $R^{2}$ is the difference between the Pseudo $R^{2}$ of the model including all covariates and the Pseudo $R^{2}$ of the model including all covariates except personality traits.

Table A3

Quantile regression results for (transformed) net non-housing wealth controlling for: personality traits of FR only (Panel1); personality traits of NFR only (Panel 2); averaged personality traits of FR and NFR (Panel 3).

\begin{tabular}{|c|c|c|c|c|c|c|c|c|c|c|}
\hline & \multicolumn{2}{|l|}{ Q10 } & \multicolumn{2}{|l|}{ Q25 } & \multicolumn{2}{|l|}{ Q50 } & \multicolumn{2}{|l|}{ Q75 } & \multicolumn{2}{|l|}{ Q90 } \\
\hline & $\beta$ & $t$ stat & $\beta$ & $t$ stat & $\beta$ & $t$ stat & $\beta$ & $t$ stat & $\beta$ & $t$ stat \\
\hline \multicolumn{11}{|c|}{ Panel 1: personality traits of FR only } \\
\hline r-Emotional stability, FR & 792 & $(0.53)$ & 1169 & $(0.77)$ & 1326 & $(0.39)$ & 5812 & $(1.15)$ & $10,565^{*}$ & $(1.94)$ \\
\hline r-Extraversion, FR & -192 & $(-0.17)$ & 1972 & $(1.36)$ & 4090 & $(1.06)$ & 4971 & $(0.95)$ & $9059^{*}$ & $(1.92)$ \\
\hline r-Openness, FR & -1634 & $(-1.36)$ & $-5228^{* * *}$ & $(-3.96)$ & -2663 & $(-0.79)$ & $-9365^{*}$ & $(-1.81)$ & $-11,262^{* * *}$ & $(-2.63)$ \\
\hline r-Agreeableness, FR & -1702 & $(-1.16)$ & -478 & $(-0.34)$ & -4350 & $(-1.32)$ & -6080 & $(-1.32)$ & -4627 & $(-0.95)$ \\
\hline r-Conscientiousness, FR & $2718^{* *}$ & $(2.21)$ & $3379^{* *}$ & $(2.31)$ & 3651 & $(1.06)$ & 7528 & $(1.37)$ & 3573 & $(0.55)$ \\
\hline
\end{tabular}




\begin{tabular}{|c|c|c|c|c|c|c|c|c|c|c|}
\hline & \multicolumn{2}{|l|}{ Q10 } & \multicolumn{2}{|l|}{ Q25 } & \multicolumn{2}{|l|}{ Q50 } & \multicolumn{2}{|l|}{ Q75 } & \multicolumn{2}{|l|}{ Q90 } \\
\hline & $\beta$ & t stat & $\beta$ & t stat & $\beta$ & $t$ stat & $\beta$ & $t$ stat & $\beta$ & t stat \\
\hline Pseudo $R^{2}$ & 0.017 & & 0.051 & & 0.104 & & 0.148 & & 0.170 & \\
\hline Personality $\Delta$ Pseudo $R^{2}$ & 0.004 & & 0.008 & & 0.004 & & 0.011 & & 0.016 & \\
\hline \multicolumn{11}{|c|}{ Panel 2: personality traits of NFR only } \\
\hline r-Emotional stability, NFR & 2580 & $(1.56)$ & -507 & $(-0.32)$ & -476 & $(-0.12)$ & 5077 & $(0.91)$ & -1794 & $(-0.31)$ \\
\hline r-Extraversion, NFR & 375 & $(0.27)$ & -190 & $(-0.10)$ & 548 & $(0.17)$ & 1088 & $(0.21)$ & -1226 & $(-0.19)$ \\
\hline r-Openness, NFR & -1136 & $(-0.71)$ & -1458 & $(-0.90)$ & -1138 & $(-0.32)$ & -3571 & $(-0.58)$ & -6589 & $(-0.92)$ \\
\hline r-Agreeableness, NFR & 318 & $(0.26)$ & 344 & $(0.22)$ & 366 & $(0.11)$ & -2772 & $(-0.57)$ & $11,939^{* *}$ & $(2.00)$ \\
\hline r-Conscientiousness, NFR & $-2767^{* *}$ & $(-2.20)$ & 512 & $(0.31)$ & 3127 & $(0.84)$ & 4342 & $(0.74)$ & 2026 & $(0.36)$ \\
\hline Pseudo $R^{2}$ & 0.016 & & 0.044 & & 0.100 & & 0.140 & & 0.162 & \\
\hline Personality $\Delta$ Pseudo $R^{2}$ & 0.003 & & 0.001 & & 0.001 & & 0.003 & & 0.008 & \\
\hline \multicolumn{11}{|c|}{ Panel 3: personality traits of FR and NFR (averaged) } \\
\hline r-Emotional stability, FR\&NFR & 1873 & $(1.02)$ & 679 & $(0.39)$ & 276 & $(0.08)$ & 5952 & $(1.09)$ & 7565 & $(1.29)$ \\
\hline r-Extraversion, FR\&NFR & 361 & $(0.23)$ & 962 & $(0.59)$ & 3003 & $(0.95)$ & 1896 & $(0.36)$ & 4651 & $(0.79)$ \\
\hline r-Openness, FR\&NFR & -953 & $(-0.73)$ & $-4123^{* * *}$ & $(-2.75)$ & -2109 & $(-0.56)$ & $-9344^{*}$ & $(-1.65)$ & $-14,260^{* * *}$ & $(-2.77)$ \\
\hline r-Agreeableness, FR\&NFR & -552 & $(-0.34)$ & -1143 & $(-0.65)$ & -3054 & $(-0.83)$ & -6137 & $(-1.34)$ & 4105 & $(0.72)$ \\
\hline r-Conscientiousness, FR\&NFR & 514 & $(0.38)$ & 1937 & $(1.13)$ & 4377 & $(1.22)$ & $9927^{*}$ & $(1.74)$ & 1305 & $(0.21)$ \\
\hline Pseudo $R^{2}$ & 0.014 & & 0.048 & & 0.103 & & 0.148 & & 0.167 & \\
\hline Personality $\Delta$ Pseudo $R^{2}$ & 0.001 & & 0.005 & & 0.003 & & 0.012 & & 0.013 & \\
\hline$N$ & 1172 & & 1172 & & 1172 & & 1172 & & 1172 & \\
\hline
\end{tabular}

Abbreviations: FR: financial respondent; NFR: non-financial respondent.

Notes: $t$ statistics in parentheses; ${ }^{*} p<0.10,{ }^{* *} p<0.05,{ }^{* * *} p<0.01$; bootstrapped standard errors computed. Net non-housing wealth has been transformed with the inverse hyperbolic sine function. Each of the personality traits has been conditioned on a polynomial in age to net out life cycle influences. The resulting personality trait is based on the standardised residual from this process, i.e. zero mean and unit standard deviation. The controls listed in Section 2.3.3 were also included. Personality $\Delta$ Pseudo $R^{2}$ is the difference between the Pseudo $R^{2}$ of the model including all covariates and the Pseudo $R^{2}$ of the model including all covariates except personality traits.

\section{References}

Ackerman, P. L., \& Heggestad, E. D. (1997). Intelligence, personality, and interests: Evidence for overlapping traits. Psychological Bulletin, 121(2), 219-245. Ameriks, J., Caplin, A., \& Leahy, J. (2003). Wealth accumulation and the propensity to plan. Quarterly Journal of Economics, 68, 1007-1047.

Ardelt, M. (2000). Still stable after all these years? Personality stability theory revisited. Social Psychology Quarterly, 63(4), $392-405$.

Barrett, A., Mosca, I., \& Whelan, B. (2015). How well-informed are pension scheme members on their future pension benefits? Evidence from Ireland. Journal of Aging \& Social Policy, 27(4), 295-313.

Barrett, A., \& O'Sullivan, V. (2014). The wealth, health and well-being of Ireland's older people before and during the economic crisis. Applied Economics Letters, 21(10), 675-678.

Bogg, T., \& Roberts, B. W. (2004). Conscientiousness and health-related behaviors: A meta-analysis of the leading behavioral contributors to mortality. Psychological Bulletin, 130(6), 887-919.

Bouchard, T. J. J. R., \& Loehlin, J. C. (2001). Genes, evolution, and personality. Behavior Genetics, 31(3), $243-273$.

Brown, S., \& Taylor, K. (2014). Household finances and the "Big Five" personality traits. Journal of Economic Psychology, 45, $197-212$.

Burbridge, J. B., Magee, L., \& Robb, L. (1988). Alternative transformations to handle extreme values of the dependent variable. Journal of the American Statistical Association, 83(401), 123-127.

Butler, G., \& Mathews, A. (1987). Anticipatory anxiety and risk perception. Cognitive Therapy and Research, 11(5), 551-565.

Cameron, C. A., \& Trivedi, P. K. (2010). Microeconometrics using Stata. Stata Press.

Carroll, C. D., Dynan, K. E., \& Krane, S. D. (2003). Unemployment risk and precautionary wealth: Evidence from households' balance sheets. The Review of Economics and Statistics, 85(3), 586-604.

Caspi, A., Roberts, B. W., \& Shiner, R. L. (2005). Personality development: Stability and change. Annual Review of Psychology, $56,453-484$.

Cheng, J. T., \& Tracy, J. L. (2013). The impact of wealth on prestige and dominance rank relationships. Psychological Inquiry, 24(2), 102-108.

Chetty, R., Friedman, J. N., Leth-Petersen, S., Nielsen, T., \& Olsen, T. (2012). Active vs. passive decisions and crowdout in retirement savings accounts: Evidence from Denmark (No. w18565). National Bureau of Economic Research.

Cobb-Clark, D. A., Kassenboehmer, S. C., \& Sinning, M. G. (2013). Locus of control and savings. Ruhr economic papers.

Cobb-Clark, D. A., \& Schurer, S. (2012). The stability of big-five personality traits. Economics Letters, 115(1), 11-15.

Conley, J. J. (1985). Longitudinal stability of personality traits: A multitrait-multimethod-multioccasion analysis. Journal of Personality and Social Psychology, 49(5), 1266-1282.

Costa, P. T., \& McCrae, R. R. (2004). A contemplated revision of the NEO five factor inventory. Personality and Individual Differences, 36(3), 587-596.

Costa, P. T., \& McCrae, R. R. (2006). Age changes in personality and their origins: Comment on Roberts, Walton, and Viechtbauer (2006). Psychological Bulletin, 132(1), 26-28.

Costa, P. T., \& McCrae, R. R. (1994). Set like plaster? Evidence for the stability of adult personality. In T. Heatherton \& J. Weinberger (Eds.), Can personality change? (pp 21-40). Washington, DC: American Psychological Association.

Costa, P. T., \& McCrae, R. R. (1997). Longitudinal stability of adult personality. In R. Hogan, J. A. Johnson, \& S. Briggs (Eds.), Handbook of personality psychology (pp. 269-290). San Diego: Academic Press.

Cottarelli, C. (2011). The challenge of public pension reform in advanced and emerging economies. International Monetary Fund<http://www.imf.org/external/ $\mathrm{np} / \mathrm{pp} / \mathrm{eng} / 2011 / 122811 . \mathrm{pdf}>$.

Davey, J., \& George, C. (2010). Personality and finance: The effects of personality on financial attitudes and behaviour. International Journal of Interdisciplinary Social Sciences, 9(5), 275-294.

Davino, C., Furno, M., \& Vistocco, D. (2014). Quantile regression. Theory and applications. John Wiley \& Sons.

Dooley, C. (2014). Methodology. In A. Nolan, C. O’Regan, \& C. Dooley, et al. (Eds.), The over 50s in a changing Ireland: Economic circumstances, health and wellbeing (pp. 187-195). Trinity College Dublin.

Duckworth, A. L. \& Weir, D. (2010). Personality, lifetime earnings, and retirement wealth. University of Michigan Retirement Research Center. WP $2010-235$. <http://www.mrrc.isr.umich.edu/publications/papers/pdf/wp235.pdf>. 
Duckworth, A. L., Weir, D., Tsukayama, E., \& Kwok, D. (2012). Who does well in life? Conscientious adults excel in both objective and subjective success. Frontiers in Psychology, 3, 356. http://dx.doi.org/10.3389/fpsyg.2012.00356.

European Central Bank (2015). The new household sector report. <https://www.ecb.europa.eu/pub/conferences/shared/pdf/2015-10-15_Household_Sector_ Report.pdf?997f1c9184574037d44ff45a0dc18a46>.

Eysenck, H. J. (1967). The biological basis of personality.Springfield, IL: Charles C. Thomas.

Gelissen, J., \& de Graaf, P. M. (2006). Personality, social background, and occupational career success. Social Science Research, 35(3), $702-726$.

Gignac, G. E., Stough, C., \& Loukomitis, S. (2004). Openness, intelligence, and self-report intelligence. Intelligence, 32(2), 133-143.

Hardcastle, R. (2012). How can we incentivise pension saving? A behavioural perspective. Department for Work and Pensions.

Heeringa, S., Hill, D. H. \& Howell, D. A. (1995). Unfolding brackets for reducing item nonresponse in economic surveys. Technical Series Paper \#95-01. Survey Research Center - Institute for Social Research, University of Michigan. <https://psidonline.isr.umich.edu/publications/Papers/tsp/1995-01_Reducing_ Item_Nonresponse.pdf>.

Heineck, G. (2011). Does it pay to be nice? Personality and earnings in the United Kingdom. Industrial \& Labor Relations Review, 64(5), 1020-1038.

Hofstede, G., \& McCrae, R. R. (2004). Personality and culture revisited: Linking traits and dimensions of culture. Cross-Cultural Research, 38(1), 52-88.

Hudson, E., Mosca, I., \& O'Sullivan, V. (2014). The economic well-being of over 50s and their children. In A. Nolan, C. O'Regan, \& C. Dooley, et al. (Eds.), The over 50s in a changing Ireland: Economic circumstances, health and well-being (pp. 25-50). Trinity College Dublin.

Judge, T. A., \& Bono, J. E. (2001). Relationship of core self-evaluations traits-self-esteem, generalized self-efficacy, locus of control, and emotional stabilitywith job satisfaction and job performance: A meta-analysis. Journal of Applied Psychology, 86(1), 80-92.

Judge, T. A., Higgins, C. A., Thoresen, C. J., \& Barrick, M. R. (1999). The big five personality traits, general mental ability, and career success across the life span. Personnel Psychology, 52(3), 621-652.

Kitchin, R., Hearne, R., \& O'Callaghan, C. (2015). Housing in Ireland: From crisis to crisis. <http://eprints.maynoothuniversity.ie/6313/>.

Kuhnen, C. M., Samanez-Larkin, G. R., \& Knutson, B. (2013). Serotonergic genotypes, neuroticism, and financial choices. PLoS ONE, 8(1), e54632.

Lauriola, M., \& Levin, I. P. (2001). Personality traits and risky decision-making in a controlled experimental task: An exploratory study. Personality and Individual Differences, 31(2), 215-226.

Luo, S., \& Klohnen, E. C. (2005). Assortative mating and marital quality in newlyweds: A couple-centered approach. Journal of Personality and Social Psychology, 88(2), 304-326.

Lusardi, A., \& Mitchell, O. S. (2007). Baby boomer retirement security: The roles of planning, financial literacy, and housing wealth. Journal of Monetary Economics, 54(1), 205-224.

McCrae, R. R. (2002). Cross-cultural research on the five-factor model of personality. Online Readings in Psychology and Culture, 4(4), 1-12.

Mroczek, D. K., \& Spiro, A. (2003). Modeling intraindividual change in personality traits: Findings from the normative aging study. The Journals of Gerontology Series B: Psychological Sciences and Social Sciences, 58(3), 153-165.

Mueller, G., \& Plug, E. (2006). Estimating the effect of personality on male and female earnings. Industrial and Labour Relations Review, 60(1), 3-20.

Nabeshima, G., \& Seay, M. (2015). Wealth and personality: Can personality traits make your client rich? Journal of Financial Planning, 28(7), 50-57.

Noftle, E. E., \& Robins, R. W. (2007). Personality predictors of academic outcomes: Big Five correlates of GPA and SAT scores. Personality Processes and Individual Differences, 93, 116-130.

Nyhus, E. K., \& Pons, E. (2005). The effects of personality on earnings. Journal of Economic Psychology, 26(3), 363-384.

Nyhus, E. K., \& Webley, P. (2001). The role of personality in household saving and borrowing behaviour. European Journal of Personality, 15, S85-S103.

Ormel, J., Bastiaansen, A., Riese, H., Bos, E. H., Servaas, M., Ellenbogen, M., Rosmalen, J. G. M., \& Aleman, A. (2013). The biological and psychological basis of neuroticism: Current status and future directions. Neuroscience and Biobehavioral Reviews, 37(1), 59-72.

Osborne Groves, M. (2005). How important is your personality? Labor market returns to personality for women in the US and UK. Journal of Economic Psychology, 26, 827-841.

O'Sullivan, V., Nolan, B., Barrett, A., \& Dooley, C. (2014). Income and wealth in the Irish longitudinal study on ageing. Economic and Social Review, 45(3), 329-348.

Ozer, D. J., \& Benet-Martinez, V. (2006). Personality and the prediction of consequential outcomes. Annual Review of Psychology, 57, 401-421.

Pence, K. M. (2006). The role of wealth transformations: An application to estimating the effect of tax incentives on saving. Contributions to Economic Analysis E'Policy, 5(1), 1-24.

Powdthavee, N., Boyce, C. J., \& Wood, A. M. (2011). Can money change who we are? Estimating the effects of unearned income on measures of incentiveenhancing personality traits. Forschungsinstitut zur Zukunft der Arbeit GmbH.

Rick, S. I., Small, D. A., \& Finkel, E. J. (2011). Fatal (fiscal) attraction: Spendthrifts and tightwads in marriage. Journal of Marketing Research, 48(2), $228-237$.

Roberts, B. W., \& DelVecchio, W. F. (2000). The rank-order consistency of personality traits from childhood to old age: A quantitative review of longitudinal studies. Psychological Bulletin, 126(1), 3-25.

Roberts, B. W., Kuncel, N. R., Shiner, R., Caspi, A., \& Goldberg, L. R. (2007). The power of personality: The comparative validity of personality traits, socioeconomic status, and cognitive ability for predicting important life outcomes. Perspectives on Psychological Science, 2(4), 313-345.

Roberts, B. W., \& Mroczek, D. (2008). Personality trait change in adulthood. Current Directions in Psychological Science, 17(1), 31-35.

Roberts, B. W., Walton, K. E., \& Viechtbauer, W. (2006). Patterns of mean-level change in personality traits across the life course: A meta-analysis of longitudinal studies. Psychological Bulletin, 132(1), 1-25.

Rothbart, M. K. (2007). Temperament, development, and personality. Current Directions in Psychological Science, 16(4), 207-212.

Schonlau, M. (2005). Boosted regression (boosting): An introductory tutorial and a Stata plugin. Stata Journal, 5(3), 330-354.

Schultz, W. P., Khazian, A. M., \& Zaleski, A. C. (2008). Using normative social influence to promote conservation among hotel guests. Social Influence, 3(1), $4-23$.

Smith, J. P., McArdle, J. J., \& Willis, R. (2010). Financial decision making and cognition in a family context. The Economic Journal, 120(548), 363-380.

Specht, J., Egloff, B., \& Schmukle, S. C. (2011). Stability and change of personality across the life course: The impact of age and major life events on mean-level and rank-order stability of the Big Five. Journal of Personality and Social Psychology, 101(4), 862-882.

Stelmack, R. M., \& Rammsayer, T. H. (2008). Psychophysiological and biochemical correlates of personality. The SAGE handbook of personality theory and assessment, 1, 33-55.

Sutin, A. R., Costa, P. T., Miech, R., \& Eaton, W. W. (2009). Personality and career success: Concurrent and longitudinal relations. European Journal of Personality, 23(2), 71-84.

Terracciano, A., McCrae, R. R., \& Costa, P. T. (2010). Intra-individual change in personality stability and age. Journal of Research in Personality, 44(1), 31-37.

Thaler, R. H., \& Benartzi, S. (2004). Save more tomorrow ${ }^{\mathrm{TM}}$ : Using behavioral economics to increase employee saving. Journal of Political Economy, 112(S1), $164-187$.

Viinikainen, J., Kokko, K., Pulkkinen, L., \& Pehkonen, J. (2010). Personality and labour market income: Evidence from longitudinal data. Labour, 24(2), 201-220.

Watson, D., Klohnen, E. C., Casillas, A., Nus Simms, E., Haig, J., \& Berry, D. S. (2004). Match makers and deal breakers: Analyses of assortative mating in newlywed couples. Journal of Personality, 72(5), 1029-1068.

Whelan, B. J., \& Savva, G. M. (2013). Design and methodology of the Irish longitudinal study on ageing. Journal of the American Geriatrics Society, 61(s2), $265-268$ 